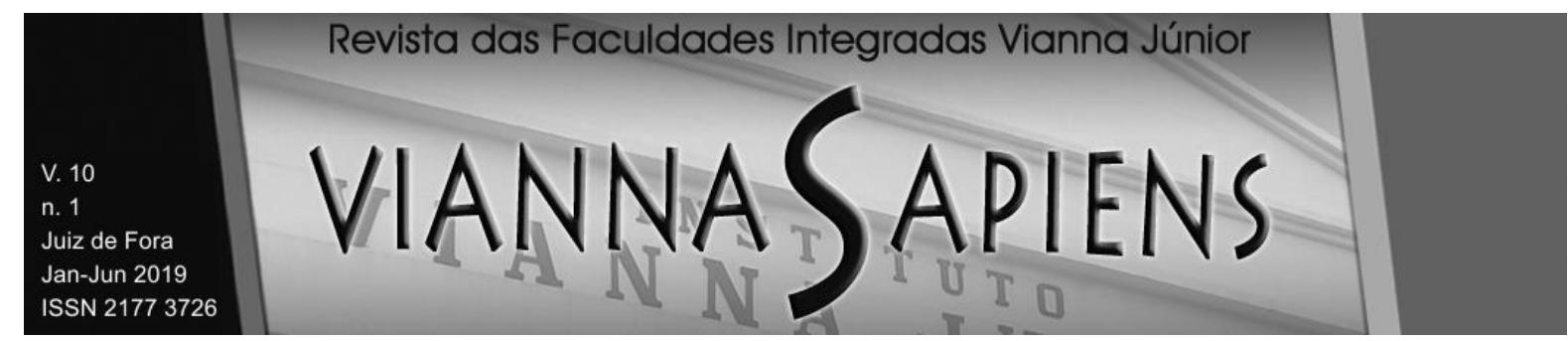

\title{
COMPATIBILIDADE ENTRE AS ÂNCORAS DE CARREIRA DOS SERVIDORES \\ DAS ATIVIDADES-FIM DO INCA E OS VALORES DA ADMINISTRAÇÃO PÚBLICA GERENCIAL
}

DOI: $10.31994 /$ rvs.v10i1.517

Fernando André Santana de Souza ${ }^{1}$
Isabel de Sá Affonso da Costa ${ }^{2}$
Marco Aurélio Carino Bouzada ${ }^{3}$

\section{RESUMO}

Este estudo analisou se os valores gerenciais incentivados a partir da Reforma Gerencial do Estado relativos à gestão de pessoas são compatíveis com os valores dos servidores das atividades-fim do Instituto Nacional de Câncer - INCA. Para analisar valores e orientações dos servidores, utilizaram-se as âncoras de carreiras de Schein. Na pesquisa quali-quantitativa aplicaram-se dois questionários: um para mapeamento das âncoras de 224 servidores e outro para especialistas em gestão de pessoas no setor público, para verificar o vínculo entre orientações da administração gerencial e âncoras. Identificou-se o ranking dos valores e das âncoras dos servidores; testes de hipóteses apontaram que os valores competitividade, inovação, autonomia e meritocracia são compatíveis com as

\footnotetext{
${ }^{1}$ Mestre em Administração pelo Programa de Mestrado em Administração e Desenvolvimento Empresarial, Universidade Estácio de Sá (MADE/UNESA). Analista em ciência e tecnologia, cedido ao Ministério da Economia. E-mail: fernandomg18@hotmail.com. ORCID: https://orcid.org/00000002-3631-8550.

2 Doutora em Administração pela EBAPE/FGV. Professora do MADE/UNESA. E-mail: isabel.costa@estacio.br. ORCID: https://orcid.org/0000-0002-4386-9385.

${ }^{3}$ Doutor em Administração pelo Instituto COPPEAD/UFRJ. Professor do MADE/UNESA. E-mail: marco.bouzada@estacio.br. ORCID: https://orcid.org/0000-0002-7183-1325.
} 


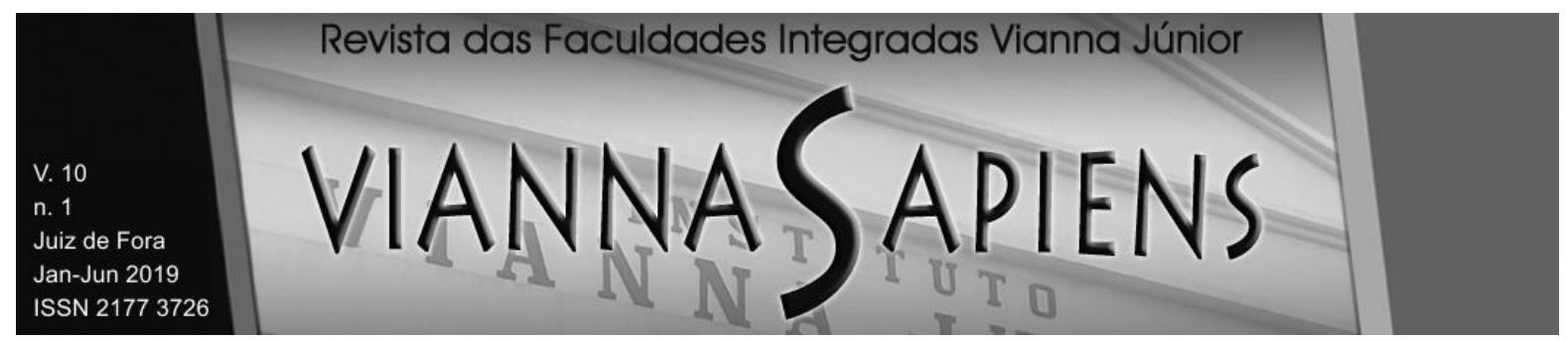

âncoras dos servidores; regressões múltiplas apontaram que o gênero impacta a compatibilidade entre âncoras e valores gerenciais. Identificar valores dos servidores apresenta-se como subsídio para políticas de gestão efetivas; o método original pode ser replicado a outras organizações.

\section{PALAVRAS-CHAVE: ÂNCORAS DE CARREIRA. VALORES. GESTÃo DE PESSOAS. GESTÃO PÚBLICA. REGRESSÃO MÚLTIPLA.}

\section{COMPATIBILITY BETWEEN CAREER ANCHORS OF INCA'S SERVERS AND THE VALUES OF MANAGERIAL PUBLIC ADMINISTRATION}

This study analyzed whether the values encouraged by the Brazilian State Reform, related to people management, are compatible with the values of the servers working in end activities of the National Cancer Institute - INCA. Servers' values and orientations were analyzed in light of Schein's career anchors. In the qualitativequantitative research, two questionnaires were applied: one for identifying the anchors of 224 servers and the other to people management specialists in public administration, to verify the link between managerial management guidelines and career anchors. The ranking of servers values and anchors were identified; tests of hypotheses pointed out that the values innovation, autonomy, meritocracy and competitiveness are compatible with the servers' anchors; multiple regressions pointed out that gender impacts the compatibility between anchors and managerial values. Identifying servers' values represents a significant subsidy to effective management policies; the original method can be applied in research in other organizations.

KEYWORDS: CAREER ANCHORS. VALUES. PEOPLE MANAGEMENT. PUBLIC MANAGEMENT. MULTIPLE REGRESSION. 


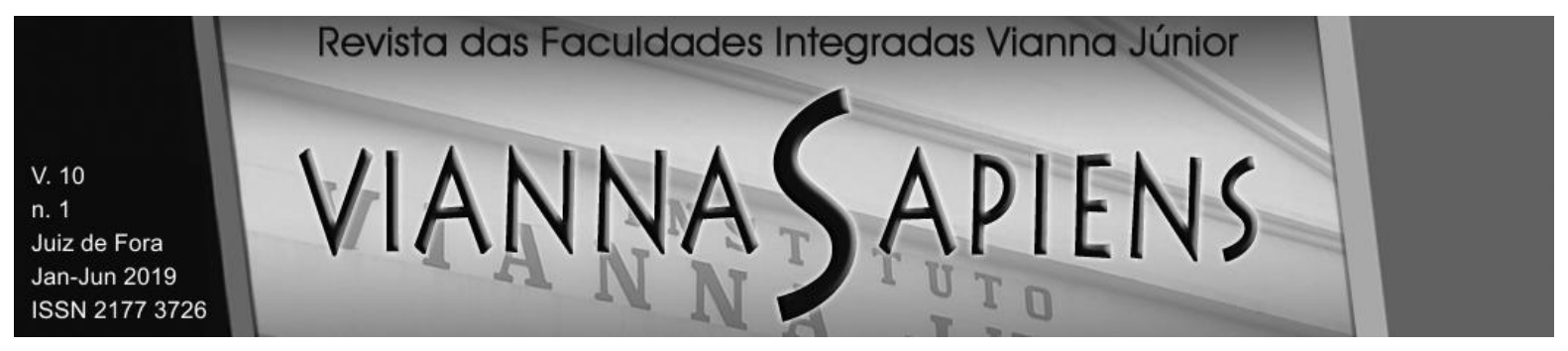

\section{INTRODUÇÃO}

A reforma administrativa, encaminhada ao Congresso Nacional em agosto de 1995, caracterizada pela intenção de transformar a administração pública burocrática em gerencial, completou, em 2018, 23 anos. Diferentemente do modelo de administração burocrática, com 0 trabalho que segue as regras claras e legalmente definidas, o respeito à hierarquia, o conhecimento especializado e a racionalidade administrativa, o modelo projetado pelo Plano Diretor da Reforma do Aparelho do Estado - PDRAE (BRASIL,1995) previa um perfil profissional mais próximo ao da gestão privada. O novo perfil profissional desejado contrapunha-se à ideologia do formalismo e do rigor técnico da burocracia tradicional; este novo perfil, que dependia da profissionalização do servidor público, estava baseado em comportamentos, valores e orientações profissionais como a autonomia administrativa, a competitividade, a inovação, a criatividade, a confiança e a meritocracia (BRESSER-PEREIRA; SPINK, 2006).

Como destaca Marconi (2005), é imprescindível reconhecer que funções diferentes implicam diferentes modelos institucionais e requisitos de gestão, que as regras dos setores públicos não devem ser necessariamente uniformes, e que as transformações nos modelos de administração envolvem alterações nas práticas objetivas e no comportamento dos trabalhadores nas organizações. Partiu-se, então, do pressuposto de que o sucesso da implementação dessas mudanças apoia-se, em grande parte, nos valores e motivações dos trabalhadores submetidos a essas transformações.

Buscou-se, com este estudo, contribuir para ampliar o conhecimento acerca dos comportamentos, valores e orientações individuais dos servidores públicos e se esses estão alinhados aos valores da administração pública gerencial, com base nas âncoras de carreiras propostas por Schein (1996). O objetivo da pesquisa foi identificar se as âncoras de carreira dos servidores que atuam nas atividades-fim do INCA são compatíveis com os valores incentivados pela administração pública 


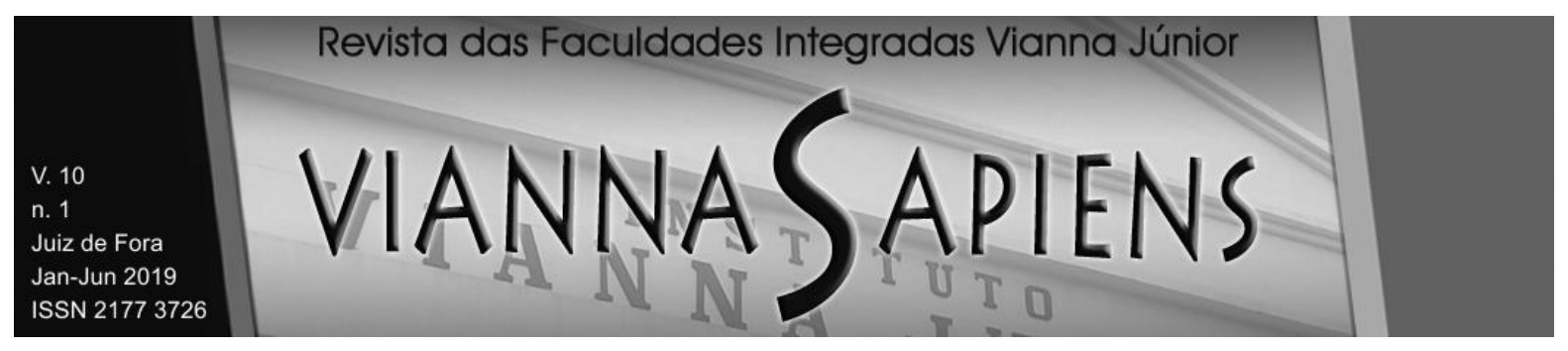

gerencial propostos no Plano Diretor da Reforma do Aparelho do Estado (BRASIL,1995) relacionados à gestão de pessoas.

Foi escolhido, por acessibilidade, o Instituto Nacional de Câncer - INCA para a realização da pesquisa. No entanto, cabe destacar que investigar uma instituição como o INCA é relevante, por esta ser referência no desempenho de suas atribuições de ensino, pesquisa, prevenção e assistência em oncologia. Além disso, presta serviços de interesse da coletividade, de forma direta e, ainda, porque o INCA acredita que seu modelo de gestão atual tenha chegado a um esgotamento, a ponto de ter sido criado, mediante a Portaria № 1.045, de 10 de dezembro de 2012 (BRASIL, 2012), um grupo de estudo que buscasse um novo modelo de gestão e que the garantisse uma maior autonomia e flexibilidade.

Conhecer e compreender os valores e expectativas dos servidores representa um importante subsídio para a implantação de novas diretrizes, políticas e práticas organizacionais, evitando que a Instituição cometa equívocos e despenda esforços sem retorno para adesão dos indivíduos ao novo modelo de gestão que se pretende efetivar. Nesse sentido, as âncoras de carreira, que consideram as motivações, atitudes e os valores individuais que guiam e as escolhas de carreira, permitem lançar luz sobre as expectativas dos servidores, que podem ser analisadas à luz das potencialidades e interesses institucionais.

Além do objetivo principal deste trabalho, também buscou-se, em caráter secundário, analisar o impacto das características individuais (sexo, idade, nível do cargo e tempo na instituição) sobre a compatibilidade entre as âncoras de carreira e cada um dos valores em análise. 


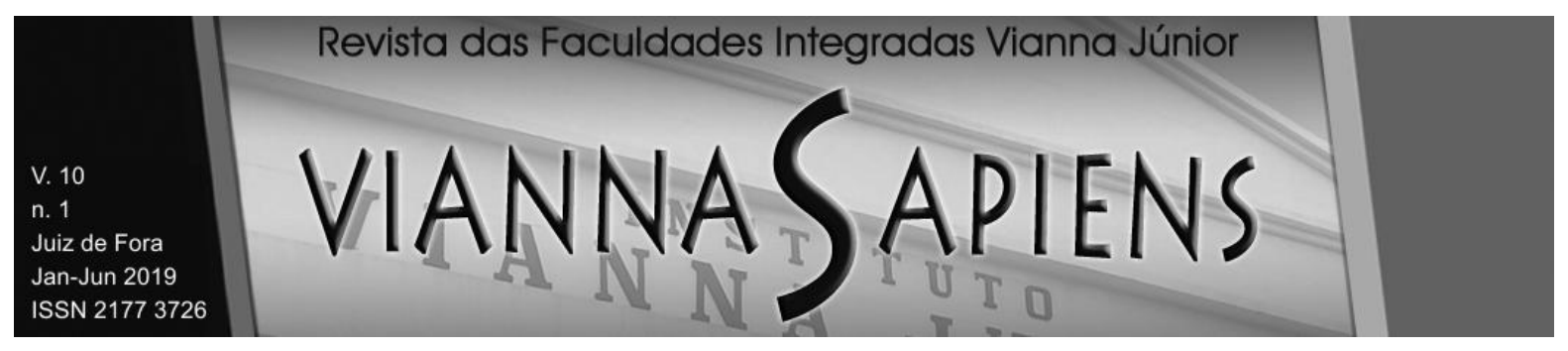

\section{REFERENCIAL TEÓRICO}

\subsection{Comportamentos e valores dos servidores públicos: desafios para a gestão de pessoas}

Um modelo de administração possui componentes formais - políticas, estruturas, normas etc - e componentes informais determinados pelas práticas dos indivíduos. Assim, é necessário entender, de forma integrada, as necessidades individuais e organizacionais, os componentes formais e informais, para dar consistência e perenidade aos modelos gerenciais (FARO, 2007).

Em relação aos componentes característicos da administração burocrática, cabe ressaltar que para Weber (MORGAN, 2002), o conceito de burocracia preconizava que a eficiência está no detalhamento antecipado e pormenorizado de como as coisas devem ser feitas, além de elementos tais como autoridade hierárquica, divisão do trabalho, competência técnica, normas de procedimentos para atuação no cargo, autoridade limitada do cargo, separação entre propriedade e administração, ênfase nas comunicações escritas e disciplina racional. Como decorrência, o burocrata weberiano é um profissional disciplinado, trabalha seguindo as regras claras e legalmente definidas, respeita a hierarquia, goza de estima social, possui conhecimento especializado e encarna o princípio da racionalidade administrativa. No entanto, a exacerbação das características weberianas gerou inúmeras críticas ao formalismo, ao apego às regras, ao grande número de níveis hierárquicos, ao desencontro de informações e falta de objetividade - efeitos conhecidos como disfunções da burocracia (MORGAN, 2002).

McGregor (1999) discute os comportamentos individuais no modelo burocrático, apontando o discutível pressuposto do controle como mecanismo fundamental de influência no comportamento dos indivíduos. Para o autor, nesse modelo os indivíduos são vistos com pouca iniciativa, sem ambição, apegados à estabilidade e propensos a fugir de responsabilidades. 


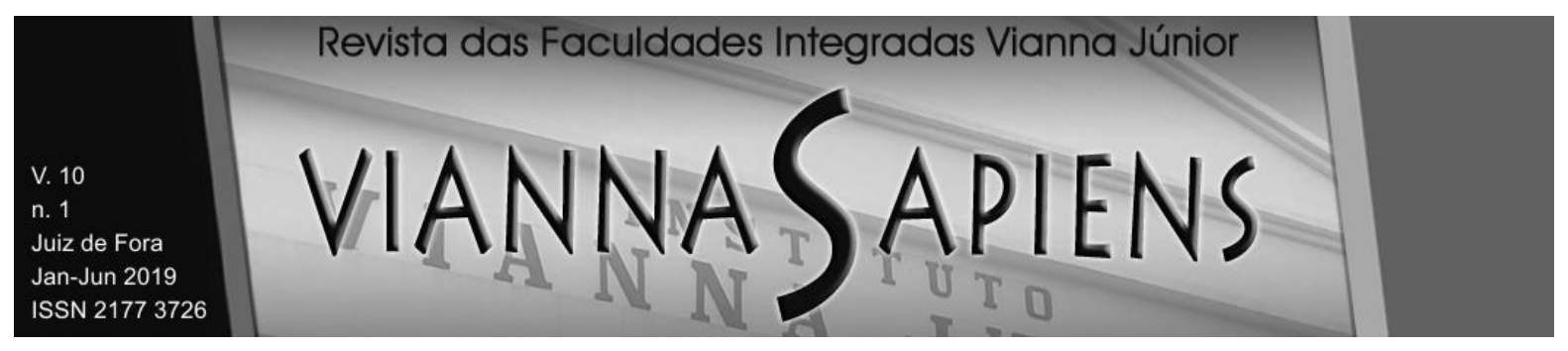

Já em relação aos componentes propostos pela reforma administrativa contida no PDRAE (BRASIL,1995), destaca-se o objetivo estratégico de se fazer uma revisão das funções do Estado, das diferentes formas de propriedade, dos tipos de administração pública e dos níveis de atividade. Pretendia-se, com a reforma, transferir para a sociedade e para outras esferas do Governo atividades que pudessem ser mais bem executadas no setor público não estatal e no âmbito dos governos estaduais e municipais. De acordo com o Plano de Governo de 1995, a reforma buscava a mudança institucional, com a renovação nos métodos de gestão, passando de rígida e ineficiente, voltada para o controle interno, para flexível e eficiente, voltada para os resultados e ao atendimento da cidadania, além da mudança para uma cultura gerencial das organizações públicas e nas leis do país (ABRUCIO, 2007; BRESSER-PEREIRA; SPINK, 2006).

O Quadro 1 consolida os valores da administração pública gerencial e da administração burocrática.

Quadro 1 - Principais valores da administração pública

\begin{tabular}{|c|c|}
\hline Gerencial & Burocrática \\
\hline Inovação & $\begin{array}{c}\text { Normas que controlam o } \\
\text { comportamento do empregado }\end{array}$ \\
\hline Autonomia & Autoridade hierárquica \\
Competitividade & Competência técnica \\
\hline Confiança & \begin{tabular}{c} 
escritas \\
\hline Meritocracia
\end{tabular} \\
\hline Criatividade & Divisão do trabalho \\
\hline
\end{tabular}

Fonte: Adaptado de PDRAE (BRASIL,1995) e Weber (apud Morgan, 2002).

Embora críticas à adoção do modelo gerencial na administração pública possam ser apontadas (COSTA, 2010), é fato que desde que a reforma administrativa foi iniciada, tem-se assistido a esforços significativos para 


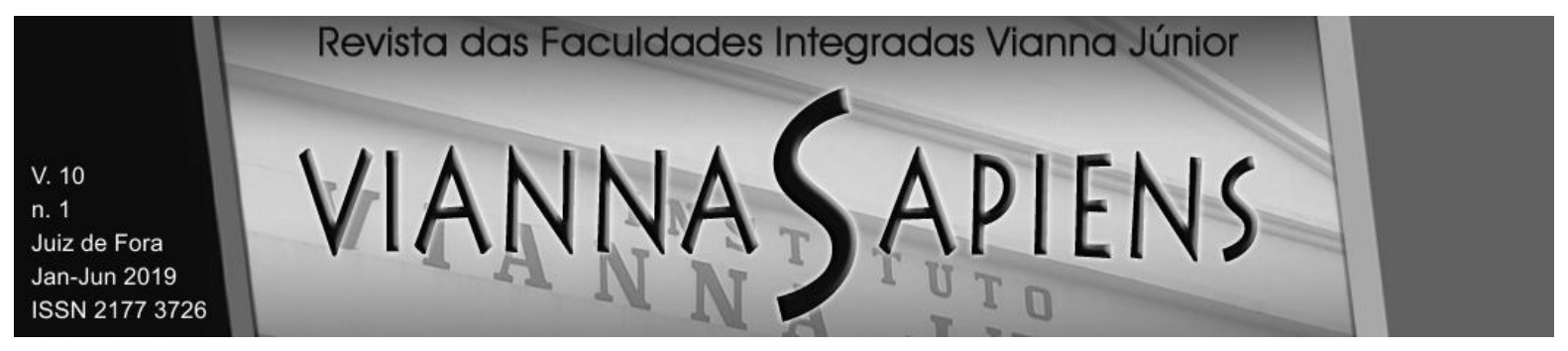

transformações da gestão de pessoas na área pública, com abordagens e arcabouços normativos que consolidam a visão estratégica da gestão de pessoas, como se vê, por exemplo, na instituição da Política Nacional de Desenvolvimento de Pessoal (AVELLINO; SALLES; COSTA, 2017).

As mudanças no mercado de trabalho e nas estruturas produtivas exigem dos profissionais atitudes "proativas", "orientadas ao mercado" e "empreendedoras" (DU GAY; SALAMAN; REES, 1996; SENNETT, 2006). Na gestão pública, a administração gerencial reflete esses valores e, em última instância, busca construir um novo modelo de administração pública.

A vida organizacional contemporânea é marcada pela transformação dos vínculos entre indivíduos e organizações. Há uma cultura da rotatividade, com laços frouxos e relações superficiais (RIBEIRO; MANCEBO, 2013; SENNET, 2006). O novo contrato psicológico de trabalho é fundado em relações mais transitórias e voltado ao cálculo da contribuição que as partes aportam aos respectivos desenvolvimentos (ROUSSEAU, 1995). Assim, partindo do perfil desejável de trabalhador contemporâneo, cabe questionar se os valores dos servidores correspondem a esse ideal, ou em que aspectos dele se distanciam.

Oliveira (2007), em estudo sobre a motivação de agentes burocráticos, se baseia na teoria da burocracia de Downs (apud OLIVEIRA, 2007), que defende que cada agente burocrático possui objetivos variados a partir do seguinte conjunto de valores, parte de uma estrutura de motivação: poder; renda; prestígio; conveniência; segurança; lealdade; orgulho por desempenho proficiente no trabalho; desejo de servir o interesse público e comprometimento com um programa específico de ação. Downs (apud OLIVEIRA, 2007) propõe cinco tipos de agente burocrático: Alpinista, Conservador, Defensor, Militante e Homem de Estado ou Estadista. Os resultados da pesquisa de Oliveira (2007) apontaram para importância dada pelos servidores públicos ao comprometimento com o seu trabalho (tipologia Defensor) e com a sociedade (tipologia Homem de Estado ou Estadista). Oliveira (2007) aponta, ainda, 


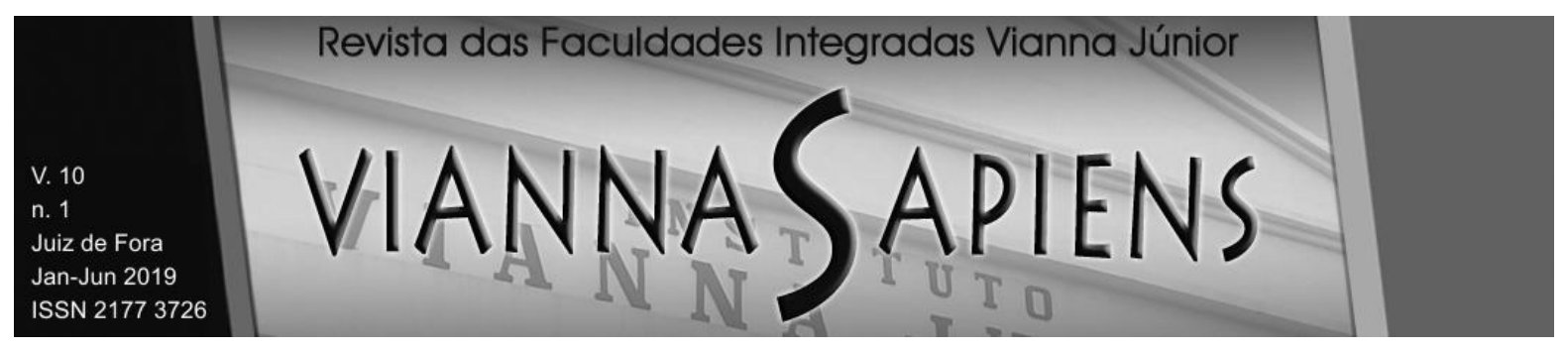

que o tempo de serviço não aparenta ser relevante para diferenciar os servidores públicos.

Também Costa, Salles e Fontes Filho (2010), em estudo sobre valores no trabalho que envolveu aproximadamente 100 profissionais de instituições públicas, privadas e híbridas, identificaram que os servidores das organizações públicas consideram, na categoria "preferência por recompensas", em 10. lugar "ter o respeito dos colegas pela qualidade do trabalho" e em $2^{\circ}$ lugar "fazer um trabalho que seja útil aos outros". Na categoria dos valores relacionados a eficácia/eficiência, os resultados revelam a convergência das preocupações dos servidores com o alcance de seus objetivos e metas e o desenvolvimento profissional. O foco prioritário é o próprio indivíduo; a preocupação com a organização (aprimoramento dos bens e serviços e utilização eficiente de recursos) ocupa as últimas posições. Esse ordenamento parece refletir discursos e práticas organizacionais correntes, como o reconhecimento baseado no desempenho e a empregabilidade. Também cabe destacar que o estudo aponta que o perfil de valores dos trabalhadores não tem diferenças significativas dos perfis dos trabalhadores dos demais setores (privado e híbrido).

Além dos valores individuais, cabe também analisar se as organizações públicas propiciam condições para o servidor desenvolver o perfil gerencial desejado. Para apontar os novos desafios da gestão de pessoas na área pública e refletir sobre o papel a ser desempenhado pelos servidores públicos no século XXI, Ribeiro e Mancebo (2013) dão ênfase aos seguintes binômios: estabilidade/instabilidade; rotina burocrática/flexibilidade e carreira linear/vínculos frouxos.

Quanto à estabilidade/instabilidade, Ribeiro e Mancebo (2013) destacam que a permanência em um mesmo local por um longo período é vista como uma acomodação do profissional e que o alto grau de exigência do setor privado se deve ao fato de não haver vagas suficientes para atender às demandas da classe trabalhadora, além das incertezas e turbulências de um mundo do trabalho 


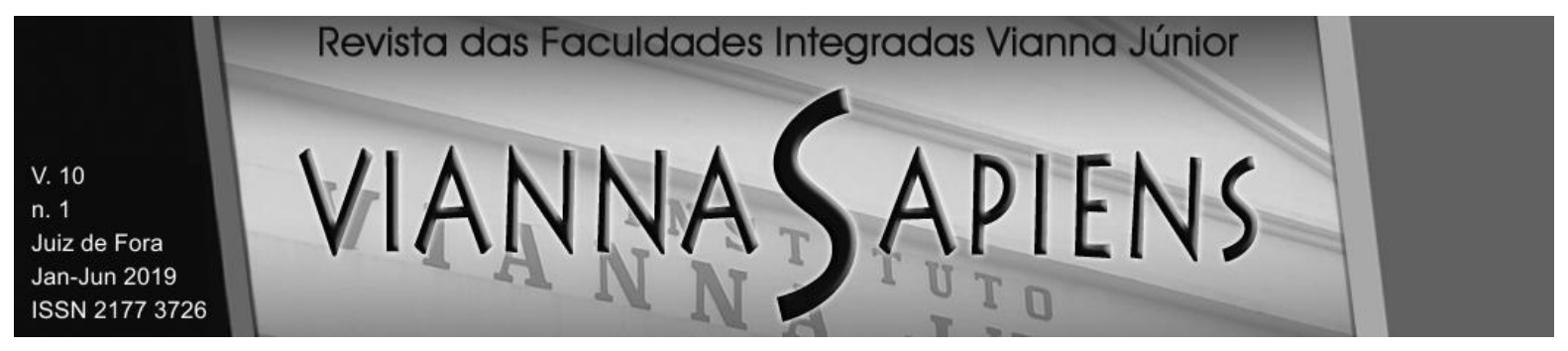

globalizado. Em relação às rotinas burocráticas/flexíveis, as autoras afirmam que a flexibilidade tornou-se imperativo organizacional e questão de sobrevivência para empresas em um mercado competitivo e globalizado. Sendo a prestação de serviços públicos voltada para necessidades não voláteis, como saúde e educação, um dos principais desafios do Estado é a adequação e flexibilidade de suas estruturas para prestar um serviço de qualidade ao cidadão. No cenário atual, a força de trabalho é reduzida, pois a administração de uma grande equipe é onerosa e um risco para a organização. Outra questão levantada pelas autoras é a transferência de atribuições para contratos precários, cujos vínculos empregatícios duradouros não são recomendados. Diante deste contexto, Ribeiro e Mancebo (2013, p. 203) fazem questionamentos importantes, dos quais vale destacar: "Como equilibrar administração flexível e manutenção dos princípios básicos do Estado de Direito?".

Por último, Ribeiro e Mancebo (2013) analisam as carreiras lineares e os vínculos frouxos, pontuando que a regularidade de uma carreira linear com a atuação em uma única empresa, a especialização em determinada atividade, o planejamento de longo prazo, a segurança em relação ao futuro e a carreira tradicional são afetadas pelo processo de reestruturação produtiva do capitalismo flexível. A concepção da constituição de carreiras lineares, associadas à verticalidade, dá lugar à mobilidade horizontal, impelindo o trabalhador a ser maleável permanentemente e a buscar sempre novas especialidades para a manutenção de sua empregabilidade.

Já para Marconi (2005), para que os novos modelos de gestão consigam atender às demandas cada vez mais rápidas da sociedade, é necessário contar com carreiras que absorvam essas mudanças, com perfis mais flexíveis e com condições de desenvolvimento contínuo dos profissionais. Outro problema apontado pelo autor é que as políticas de recursos humanos voltadas para a estabilidade, segurança, o aumento de salário de acordo com o tempo de serviço e a aposentadoria integral, características da administração pública burocrática, não criaram condições para a inovação, melhoria do desempenho e da produtividade. Como consequência, gerou- 


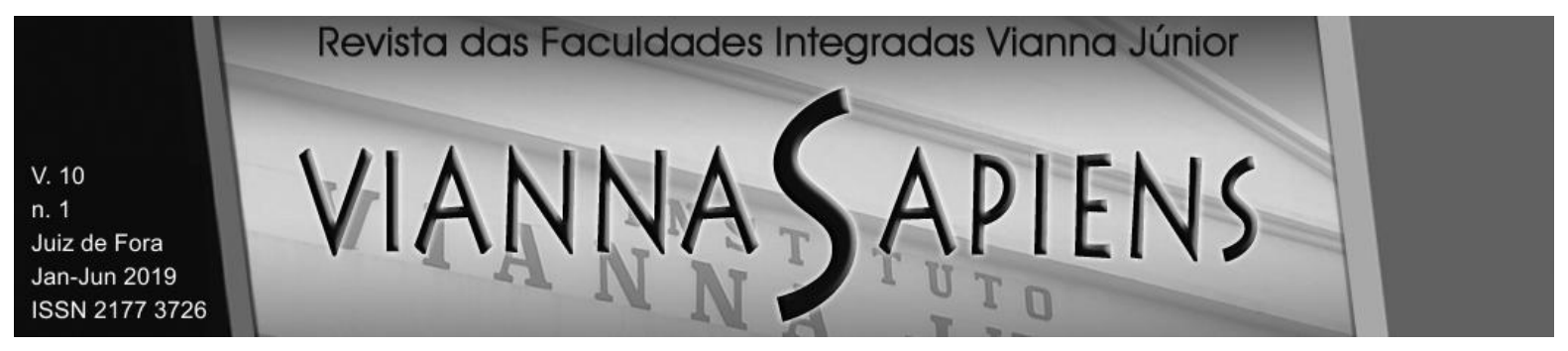

se um quadro de profissionais com bastantes conhecimentos técnicos e específicos do processo de trabalho, mas pouco atualizado - daí, em geral, não corresponderem às necessidades atuais das populações e dos governos.

Como saída ao contexto apresentado, Marconi (2005) sugere a realização de um planejamento estratégico capaz de definir as funções e atividades que serão desempenhadas pela organização no futuro, o que será fundamental para determinar os processos de trabalho com suas competências, atribuições, bem como o número e o perfil dos servidores necessários. Este planejamento deve estabelecer, além dos princípios norteadores, um recrutamento eficiente, rigoroso, rápido e contínuo (evitando hiatos entre gerações) de servidores com o perfil necessário. Deve estabelecer também uma estrutura de carreira que promova a mobilidade horizontal com trocas de conhecimento e habilidade e que estimule o servidor a buscar o aprimoramento de sua capacitação e desempenho, e ainda que, ao mesmo tempo, permita ao gestor cobrar os resultados. Um terceiro aspecto é a elaboração de uma estratégia de capacitação contínua. Outro enfoque importante é a criação de uma estrutura de incentivos, com progressões associadas ao acúmulo de competências, atribuições e ao desempenho do funcionário, e não ao tempo de serviço. Além dos aspectos apresentados, podem-se mencionar outros, tais como: uma estrutura de avaliação que tente neutralizar o caráter subjetivo da avaliação, permitindo verificar 0 desempenho do servidor em relação às metas preestabelecidas e identifique necessidades de capacitação; além de uma estratégia de realocação e redistribuição de servidores por meio de um banco de talentos. Cabe ressalvar, como apontado por Bergue (2014), que a gestão estratégica de pessoas, no setor público, deve ter como ponto de partida a missão institucional - 0 que nem sempre favorece objetivos facilmente mensuráveis.

Assim, cabe refletir se as diversas tentativas e propostas, respeitando as características de cada organização, vão permitir a construção de um desenho que exiba uma consistência interna e proponha, de fato, melhorias na gestão de pessoas. Outra questão a ser avaliada é o quão interessante é para o servidor 


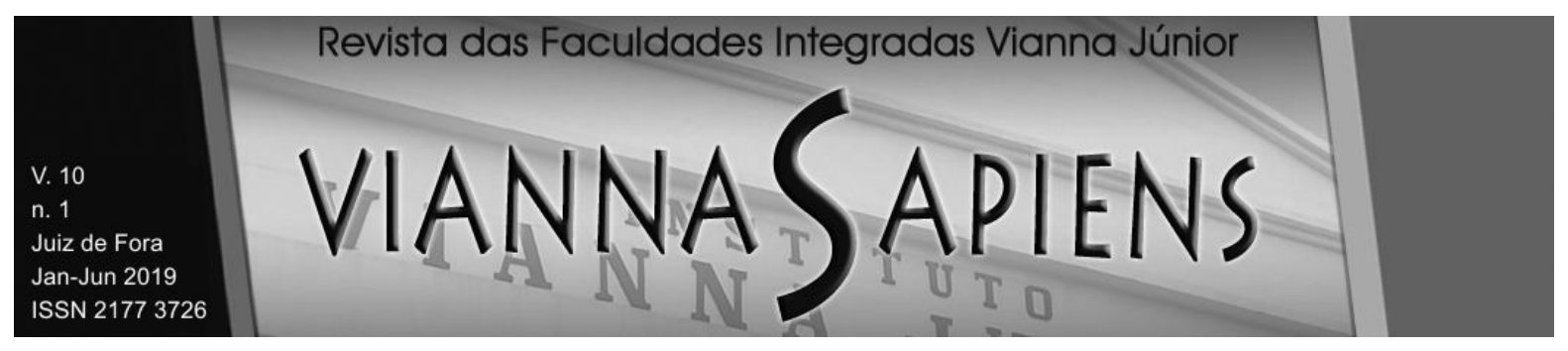

público transformar-se em um trabalhador autônomo ou empreendedor, se há possibilidades deste profissional ampliar e diversificar suas atribuições e, ainda, conforme apontam Ribeiro e Mancebo (2013), questionar a quem serve este padrão de profissional. Mesmo com todas as mudanças em curso e que se projetam no Brasil em relação aos servidores públicos, é fato que as carreiras públicas ainda são buscadas por sua estabilidade (ALBRECHT; KRAWULSKI, 2011) - o que tende a ensejar vínculos de longo prazo, mesmo em face da "cultura da rotatividade" contemporânea.

\section{2 Âncoras de Carreira de Edgard Schein}

Schein (1974) define âncora de carreira como o conjunto de fatores da autopercepção do qual o indivíduo não abre mão diante das escolhas profissionais, mesmo diante de escolhas difíceis. A autopercepção leva em consideração as motivações, atitudes e os valores individuais que guiam e restringem a carreira de uma pessoa. Para o autor, os indivíduos apresentam necessidades correspondentes às diferentes âncoras de carreira, diferenciando-se uns dos outros de acordo com o peso que é dado a cada âncora. As âncoras são a parte estável e conservadora da personalidade do indivíduo e funcionam para puxar a pessoa de volta, se as experiências profissionais se desviam do que realmente ela deseja. $O$ autor identificou a existência de padrões de escolha de experiências profissionais em função das diferentes autopercepções, o que permitiu a categorização em oito tipos de âncoras:

- Competência Técnica/Funcional (Technical/Functional): profissionais com grande motivação para experiências de trabalho em que se sintam desafiados a explorar suas capacidades técnicas.

- Competência gerencial (Managerial competence): esta âncora exerce uma força sobre o indivíduo na direção de ter oportunidade de liderar, tomar 


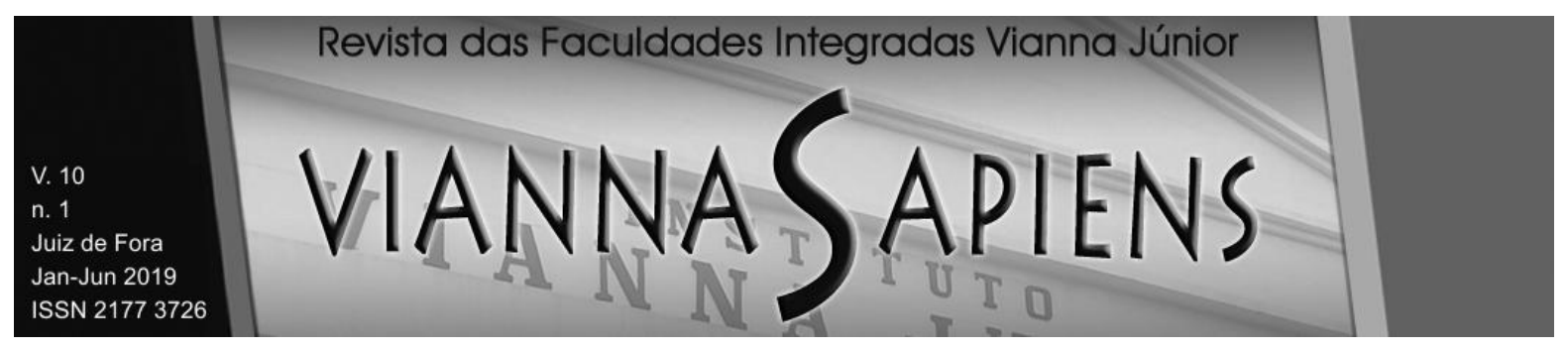

decisões e definir diretrizes de impacto organizacional. Valorizam recompensas relacionadas a títulos e status.

- Autonomia/Independência (Autonomy/Independence): valorização as experiências profissionais nas quais o indivíduo possa realizar seu trabalho à sua própria maneira; os indivíduos consideram a vida organizacional restritiva, irracional e uma intromissão em suas vidas pessoais, o que faz preferirem uma carreira autônoma, com suas próprias condições.

- Segurança/Estabilidade (Security/Stability): valorização das experiências profissionais que propiciem uma sensação de segurança e estabilidade. São valorizados os sentimentos de lealdade para com a organização e a previsibilidade das tarefas a serem executadas.

- Criatividade empreendedora (Entrepreneurial Creativity): indivíduos com esta âncora valorizam a possibilidade de estabelecer, criar e estruturar organizações, negócios, produtos e serviços; têm disposição para largar um trabalho previamente existente. São profissionais inquietos, egocêntricos, que procuram novos desafios constantemente.

- Senso de dever/dedicação a uma causa (Service/Dedication to a cause): valorização das experiências profissionais que viabilizem o alinhamento entre os seus valores fundamentais e os valores do grupo ou da organização a qual pertence; o sucesso está em contribuir para um mundo melhor.

- Puro desafio (Pure Challenge): valorização da competição e de experiências profissionais que viabilizem desafios cada vez maiores; sucesso é a superação de obstáculos impossíveis, solução de problemas insolúveis ou vitória sobre oponentes extremamente difíceis.

- Estilo de vida (Lifestyle): valorização de experiências profissionais que permitam uma integração, ou equilíbrio, entre as necessidades pessoais, da família e as profissionais. Esta âncora não preconiza um indivíduo negligente 


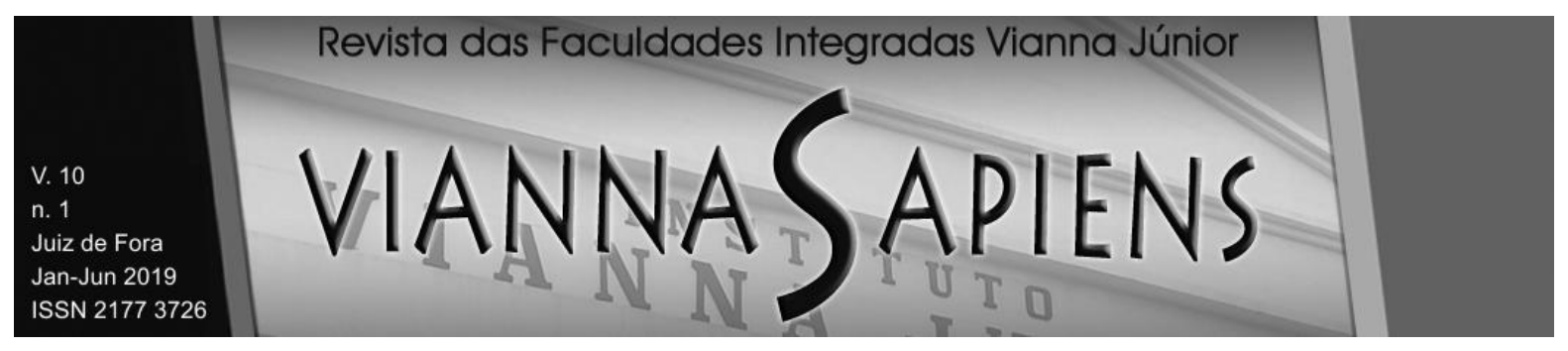

no trabalho, mas apenas ele não o considera como o centro de sua existência.

Abdalla (2003) destaca que as âncoras ajudam a compreender as escolhas profissionais do indivíduo e podem ser utilizadas isoladamente ou aliadas a outros instrumentos de gestão de recursos humanos. Em consonância, Van Dam (2004) espera que as organizações viabilizem carreiras congruentes com as âncoras de carreira dos trabalhadores, pois, caso contrário, poderá haver consequências como insatisfação, baixo desempenho e rotatividade de pessoal. Do mesmo modo, se o modelo gerencial aponta para comportamentos, atitudes e valores como a autonomia, a competitividade, a inovação, a confiança, a meritocracia e a criatividade, torna-se relevante compreender quais as possíveis influências das âncoras desse grupo de estudo na implantação de práticas inerentes a este modelo.

\section{METODOLOGIA}

Este estudo buscou quantificar opiniões e dados das âncoras de carreira dos servidores utilizando técnicas e recursos estatísticos - configurando uma abordagem quantitativa.

Já para a análise dos especialistas quanto à compatibilidade das âncoras de carreira com os valores da administração pública gerencial, optou-se pela abordagem qualitativa, uma vez que não se dispõe de grande quantidade de informações dos assuntos (tratados de forma conjunta), sendo necessário explorar o conhecimento que os especialistas possuem com base em suas experiências ou senso comum. Este procedimento metodológico, de consulta a especialistas, é bastante encontrado em trabalhos que utilizam a Lógica Fuzzy (KLIR; YUAN, 1995), justamente para lidar com temas sem tanta informação disponível, ou seja, ainda nebulosos. 


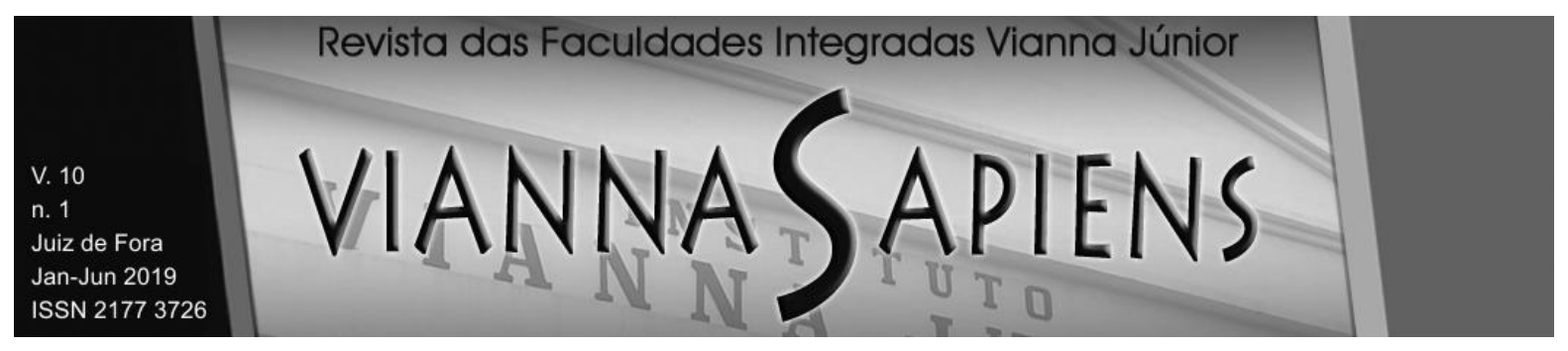

Em vista do exposto, a abordagem da presente pesquisa foi qualiquantitativa.

Nesta pesquisa, a população foi de aproximadamente 2417 servidores efetivos que atuam diretamente nas atividades-fim da do INCA (INCA, 2015). A amostra da pesquisa foi constituída pelos profissionais das atividades-fim que responderam de maneira satisfatória aos questionários, compondo-se uma amostra de 224 respondentes. Fazem parte das atividades fins do INCA os profissionais ligados às atividades de assistência, ensino, pesquisa e da área de políticas de controle e prevenção do câncer.

Aplicaram-se dois questionários estruturados, um para os funcionários do INCA e outro para os especialistas em gestão de pessoas na área pública.O questionário, adaptado de Schein (1996), teve como objetivo classificar as âncoras de carreira dos servidores e identificar as características individuais: sexo, idade, nível do cargo, profissão e tempo na organização.

O tema da pesquisa vinculou duas teorias: Administração Pública Gerencial, formalizada pelo PDRAE (BRASIL, 1995), e as âncoras de carreira de Schein (1996). Não foi possível encontrar na literatura científica estudos que vinculem os valores estabelecidos por ambas. Assim buscou-se, de maneira similar ao que ocorre na aplicação da lógica Fuzzy (ZIMMERMANN, 1996), verificar a intensidade do vínculo entre cada orientação da administração gerencial e cada âncora de carreira, através da opinião de autoridades acadêmicas especializadas e reconhecidas tanto na área de gestão de pessoas, quanto na área de gestão pública.

O tratamento de dados para identificar, segundo o conceito de âncoras de carreira, se as orientações profissionais dos servidores do INCA são compatíveis com as orientações da administração pública gerencial, seguiu os seguintes passos:

O primeiro foi o tratamento de dados dos questionários aplicados aos especialistas. Após a atribuição dos graus de 0 a 10 para a relação entre cada âncora e cada orientação da administração gerencial, calculou-se a média aritmética dos três especialistas e, consequentemente, foi possível identificar a 


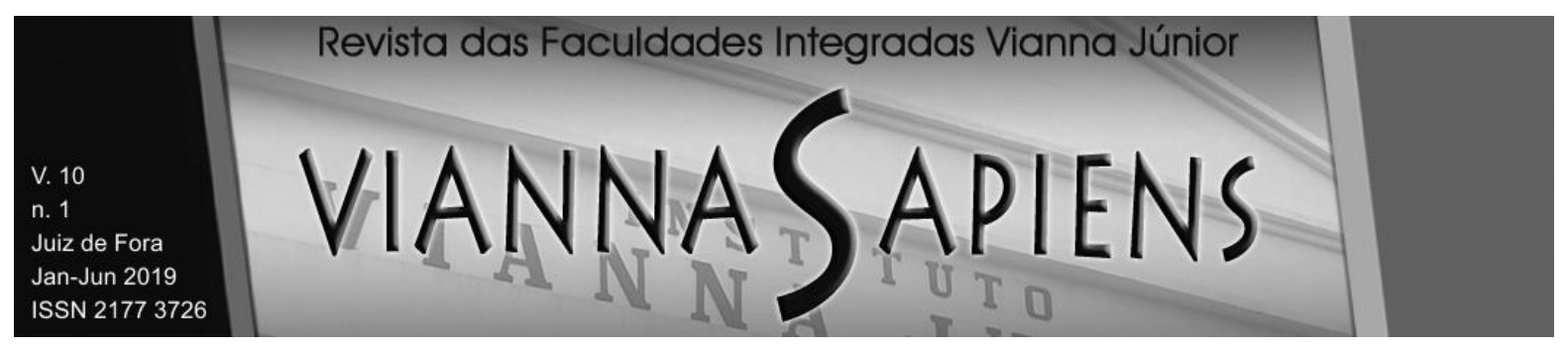

correspondência média entre as orientações da administração gerencial e as âncoras de carreira.

O segundo passo, de posse dos questionários respondidos pelos servidores das atividades-fim do INCA, foi calcular as médias de cada âncora para cada funcionário, de acordo com o método proposto por Schein (1996).

Em seguida, encontrou-se o valor que relacionou as âncoras de carreira com as orientações da administração gerencial, para cada funcionário. Para cada valor incentivado pelas orientações da administração gerencial (autonomia administrativa, competitividade, inovação, criatividade, confiança e meritocracia), encontrou-se a média ponderada dos escores de cada âncora, de cada funcionário, sendo que os pesos e as intensidades do vínculo entre cada orientação e cada âncora foram atribuídos pelos especialistas.

$\mathrm{Na}$ etapa seguinte calculou-se, para cada valor incentivado pelas orientações da administração gerencial, a média de pontuação de todos os funcionários. Comparando-se essas médias, foi possível identificar quais valores foram mais e menos alinhados com as âncoras de carreira dos funcionários do INCA.

Após identificar-se o ranking de "valores" do INCA, verificou-se, por meio de seis testes de hipóteses para a média, se a média de cada valor incentivado pelas orientações da administração gerencial superou o ponto médio da escala de 1 a 6 $(3,5)$.

Finalmente, para a análise do impacto das características pessoais (sexo, idade, nível do cargo e tempo na instituição) sobre a compatibilidade entre as âncoras de carreira e as orientações do modelo gerencial, foram realizadas seis regressões múltiplas (uma para cada valor incentivado pelas orientações da administração gerencial) para tentar explicar a intensidade daquele valor presente em cada funcionário em função das quatro variáveis explicativas - as características individuais.

Como o sexo e o cargo (variáveis independentes do modelo de regressão múltipla) não são numéricas, foram utilizadas variáveis dummy para incluí-las no 


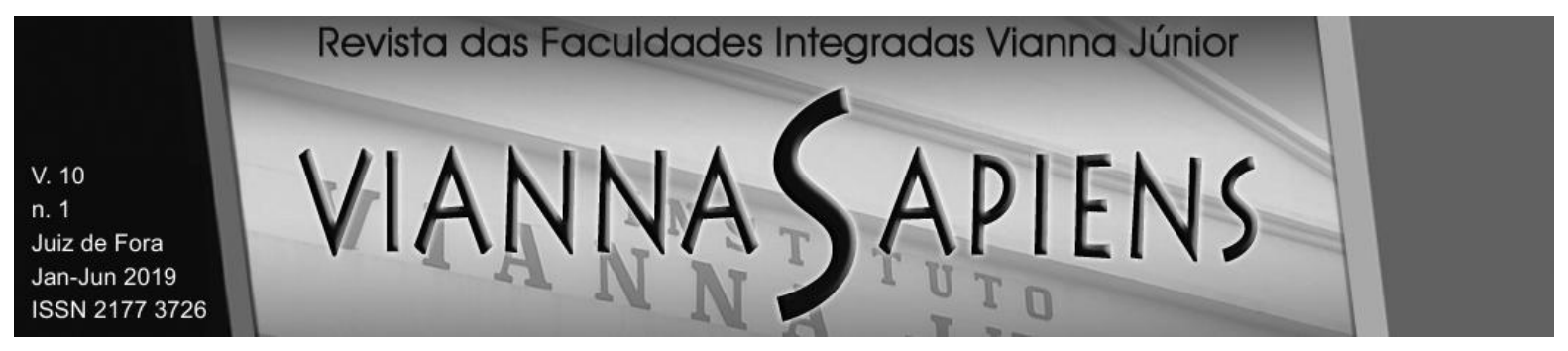

modelo de regressão. A primeira assumiu os valores masculino ou feminino; a segunda, técnico, técnico superqualificado ou superior.

A metodologia escolhida para a coleta e tratamento dos dados apresentou as principais dificuldades: o viés de não resposta; a escolha por acessibilidade e a subjetividade dos especialistas nas respostas aos questionários; a necessidade de se pesquisar todos os cargos da administração pública, independente de sua finalidade e órgão, assim como a de realizar estudos comparativos ao longo do tempo. Todavia, mesmo com as limitações apontadas, considera-se que este foi o método mais apropriado para que os objetivos da pesquisa fossem alcançados.

\section{APRESENTAÇÃO E ANÁLISE DOS RESULTADOS}

$\mathrm{Na}$ primeira etapa da pesquisa, as respostas dos três especialistas ao questionário estruturado permitiu identificar, de maneira original, a correspondência entre cada âncora de carreira e cada valor da administração gerencial, como retratado na Tabela 1. Na Tabela destacam-se as correspondências (maiores ou iguais a 8) entre as seguintes âncoras $x$ valores:

- "Autonomia e independência" x "Autonomia administrativa";

- "Criatividade empreendedora" x "Inovação";

Destacam-se também as fracas correspondências (menores ou iguais a 4) entre as seguintes âncoras $x$ valores:

- A âncora "Segurança e estabilidade", com os valores: "Criatividade" "Inovação" e "Competitividade";

- A âncora "Estilo de vida", com cinco diferentes valores: "Criatividade, Inovação, Meritocracia, Confiança e Competitividade). 


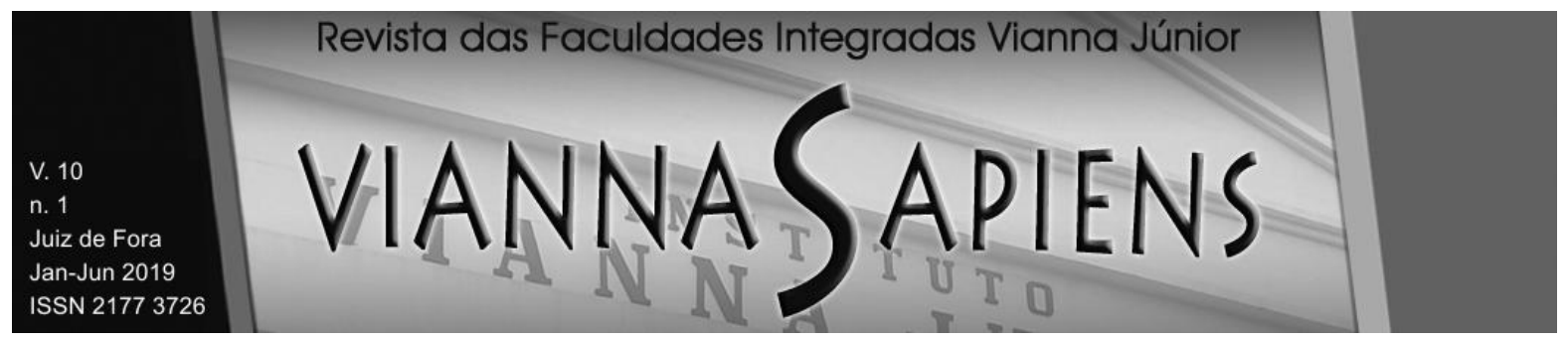

Tabela 1 - Correspondência média entre as orientações da administração gerencial e as âncoras de carreira, de acordo com os especialistas

\begin{tabular}{|l|r|r|r|r|r|r|r|r|}
\hline Valor/âncora & $\begin{array}{c}\text { Competência } \\
\text { técnica/ } \\
\text { funcional }\end{array}$ & $\begin{array}{c}\text { Competência } \\
\text { Gerencial }\end{array}$ & $\begin{array}{c}\text { Autonomia e } \\
\text { Idependência }\end{array}$ & $\begin{array}{c}\text { Segurança e } \\
\text { Estabilidade }\end{array}$ & $\begin{array}{c}\text { Senso de } \\
\text { Criatividade } \\
\text { Empreendedora } \\
\text { dedicação } \\
\text { a uma } \\
\text { causa }\end{array}$ & $\begin{array}{c}\text { Puro } \\
\text { Desafio }\end{array}$ & $\begin{array}{c}\text { Estilo de } \\
\text { Vida }\end{array}$ \\
\hline Criatividade & 5,0 & 7,0 & 7,7 & 3,7 & 6,7 & 6,0 & 4,7 & 3,0 \\
\hline Inovação & 6,0 & 6,7 & 5,7 & 3,7 & 8,0 & 4,0 & 4,7 & 3,0 \\
\hline Autonomia Administrativa & 6,3 & 6,7 & 8,0 & 5,0 & 5,7 & 7,0 & 4,7 & 4,7 \\
\hline Meritocracia & 7,3 & 7,3 & 7,3 & 4,7 & 6,3 & 5,7 & 5,7 & 4,0 \\
\hline Confiança & 7,0 & 7,0 & 7,0 & 4,7 & 4,7 & 8,0 & 4,0 & 4,0 \\
\hline Competitividade & 4,3 & 4,3 & 4,7 & 3,3 & 4,7 & 3,3 & 5,7 & 3,0 \\
\hline
\end{tabular}

Fonte: Dados da pesquisa.

Quanto às informações das características demográficas dos 224 respondentes, $75 \%$ eram mulheres e $25 \%$ eram homens. A idade média desses profissionais é de 37 anos. A experiência média encontrada foi de 2 anos, mas destacou-se o fato de aproximadamente $80 \%$ da amostra possuir experiência na instituição de menos de 1 ano. Não foi mensurada a experiência desses trabalhadores em outras instituições.

Em relação ao nível de escolaridade do cargo dos servidores da amostra, aproximadamente $58 \%$ foram contratados para exercer suas funções em cargo de nível superior e 42\% para exercer funções de nível médio. Quanto à escolaridade, aproximadamente $83 \%$ dos servidores da amostra têm nível superior completo, 9\% nível médio e $8 \%$ têm nível superior em curso. Foram entrevistados servidores de 22 diferentes profissões, o que evidencia a heterogeneidade da amostra (ver Tabela 2).

Tabela 2 - Formação do cargo contratado dos participantes

\begin{tabular}{|l|c|}
\hline Qual a formação do cargo contratado dos participantes? & Total \\
\hline Biólogo & 7 \\
\hline Biomedicina & 3 \\
\hline Enfermagem & 53 \\
\hline Farmácia & 4 \\
\hline Fisioterapia & 3 \\
\hline
\end{tabular}




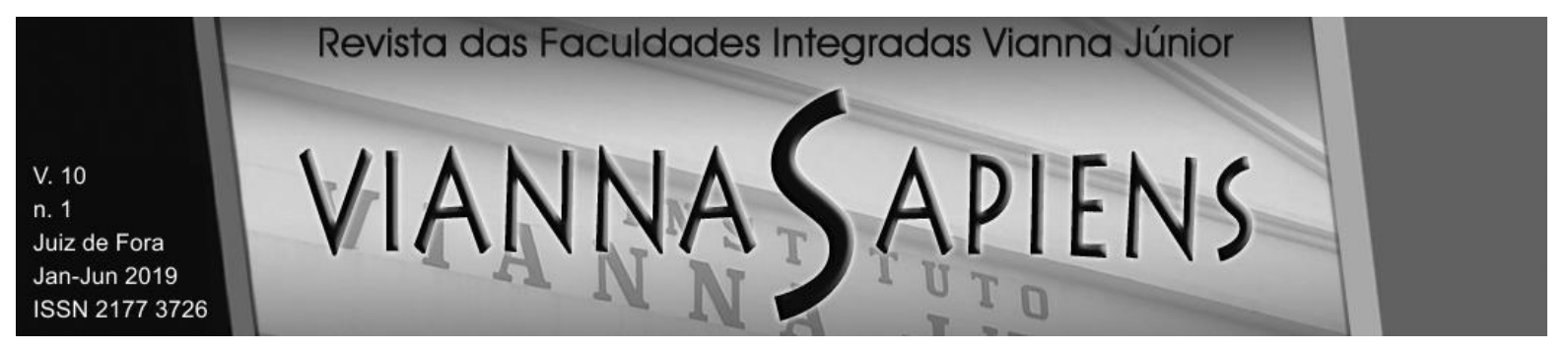

\begin{tabular}{|l|c|} 
Medicina & 47 \\
\hline Medicina veterinária & 1 \\
\hline Nutrição & 3 \\
\hline Odontologia & 1 \\
\hline Psicologia & 3 \\
\hline Serviço social & 4 \\
\hline Técnico de enfermagem & 65 \\
\hline Técnico farmácia & 2 \\
\hline Técnico funcional respiratório & 1 \\
\hline Técnico análise clínica & 1 \\
\hline Técnico de anatomia patológica & 5 \\
\hline Técnico citotécnico & 6 \\
\hline Técnico de criação de animais de laboratório & 1 \\
\hline Técnico de hemoterapia & 3 \\
\hline Técnico prótese dentária & 1 \\
\hline Técnico de radiologia & 3 \\
\hline Técnico de radioterapia & 7 \\
\hline Total de Profissionais & 224 \\
\hline
\end{tabular}

Fonte: Dados da Pesquisa.

Dando continuidade aos procedimentos de pesquisa, foi calculada a média de cada funcionário, em cada âncora. As principais âncoras de carreira dos profissionais das áreas-fim do INCA são apresentadas na Tabela 3.

Tabela 3 - Ranking das âncoras de carreira dos servidores do INCA

\begin{tabular}{|l|l|l|}
\hline $1^{\underline{a}}$ & "Senso de dever, dedicação a uma causa" & 5,06 \\
\hline $2^{\underline{a}}$ & "Estilo de vida" & 5,03 \\
\hline $3^{\underline{0}}$ & "Segurança e Estabilidade & 4,89 \\
\hline $4^{\underline{a}}$ & "Competência técnica/funcional" & 4,38 \\
\hline $5^{\underline{a}}$ & "Puro desafio" & 4,08 \\
\hline $6^{\underline{a}}$ & "Autonomia e Independência" & 3,08 \\
\hline $7^{\underline{a}}$ & "Competência gerencial" & 2,63 \\
\hline $8^{\underline{a}}$ & "Criatividade empreendedora" & 2,41 \\
\hline
\end{tabular}

Fonte: Dados da pesquisa.

Pelos resultados, depreenderam-se alguns aspectos importantes, como a similaridade dos resultados das âncoras de carreira dos servidores do Tribunal de 


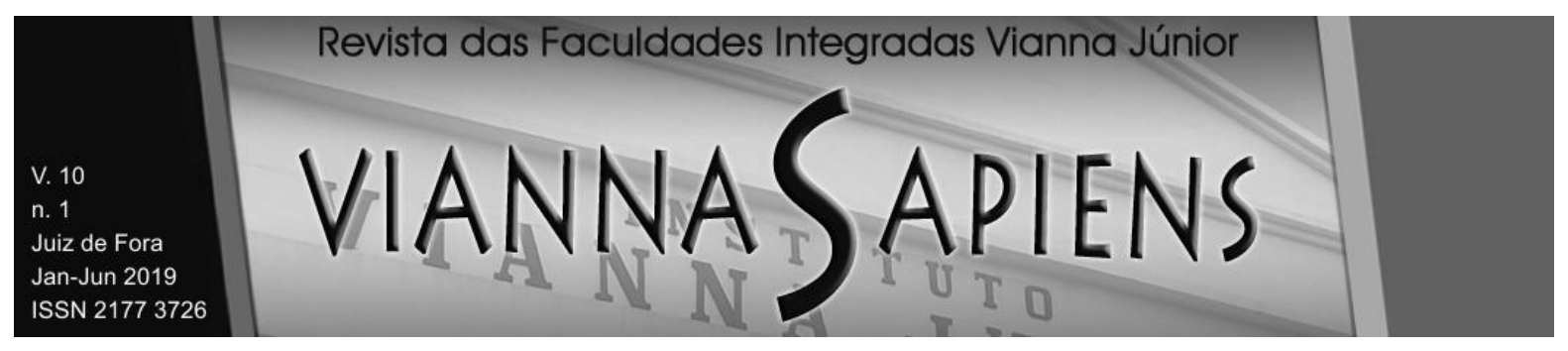

Contas da União (TCU) encontrados por Faro (2007) e as âncoras dos profissionais da áreas-fim do INCA. Em ambos os estudos, as âncoras "estilo de vida", "senso de dever, dedicação a uma causa", "segurança e estabilidade" e "competência técnica/funcional" estiveram nas primeiras colocações. Já as âncoras "puro desafio", "autonomia e independência", "competência gerencial" e "criatividade empreendedora" aparecem com escores menores entre os servidores pesquisados.

Estes resultados, encontrados no INCA, ganham respaldo naqueles obtidos nos estudos de Costa, Salles e Fontes Filho (2010), quando estes, com base em Tamayo e Gondim (1996) e Wittmer (1991), pesquisaram aproximadamente 100 profissionais de diferentes formas de instituição (pública, privada e híbrida) e encontraram, no que se refere às preferências por recompensas, que os trabalhadores das organizações públicas consideram, em segundo lugar, a oportunidade de realizarem um trabalho que seja útil aos outros, o que se aproxima da âncora "senso de dever, dedicação a uma causa" (tida como a principal âncora do INCA). Ao mesmo tempo, nesse mesmo estudo, os autores observaram que os itens segurança e emprego, promoção e conquista de status e prestígio - que se aproximam da âncora "segurança e estabilidade" -, ocupam os últimos lugares no ranking. Desse modo, concluíram que os valores encontrados "distanciam-se do estereótipo do servidor público que valoriza a segurança acima de tudo" (COSTA; SALLES; FONTES FILHO 2010, p. 1447).

Alguns dos resultados encontrados neste estudo também vão ao encontro da contribuição de Oliveira (2007), cuja pesquisa com mais de 200 profissionais da administração pública federal não verificou a existência exata e pura de uma tipologia proposta por Downs (1967). Entretanto, pode-se concluir, de maneira consistente, que, dos tipos propostos na tipologia de Downs, o "tipo defensor" que "veste a camisa"- permeou todos os aglomerados, sinalizando o comprometimento do servidor público com o seu trabalho. De forma análoga, o "tipo Homem de Estado ou Estadista", também presente em todos os aglomerados, retratou o comprometimento com a sociedade. Quanto à estabilidade, assim como em outros 


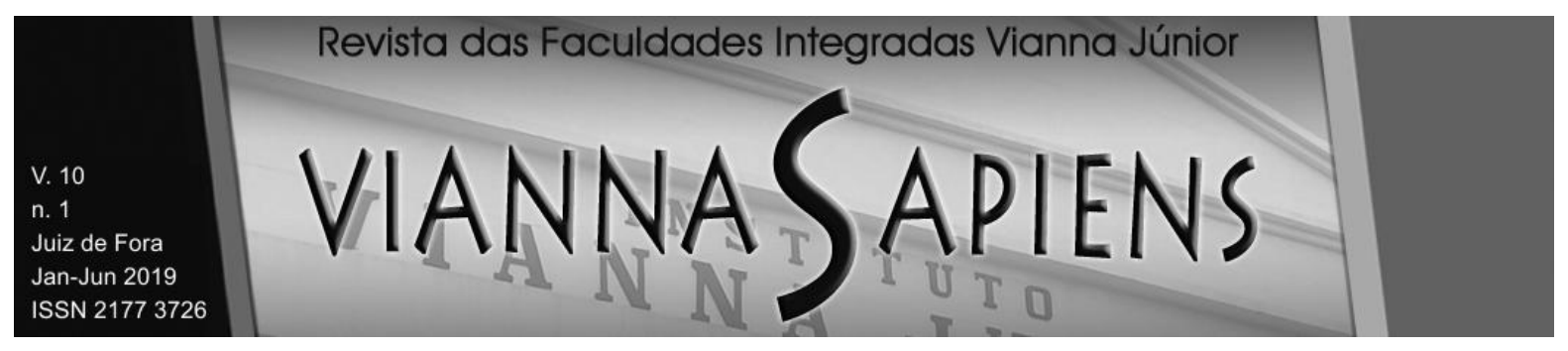

estudos, Oliveira (2007) depreende que este fator merece certa relevância como um atrativo, mas a estabilidade não foi considerada como um item "acima de tudo" para os servidores.

Observa-se que o conjunto de valores ligados ao compromisso dos servidores públicos brasileiros com o trabalho e com a sociedade foi encontrado, em diferentes épocas, estudos e metodologias distintas, por diferentes autores. Este fato, diferentemente do que ocorre no setor privado, onde há diversos incentivos, induz a uma reflexão quanto ao fato dos profissionais da administração pública, se considerarmos a amostra estudada, "vestirem a camisa" sem que, muitas vezes, sejam intencionalmente encorajados a isso pela organização.

É possível especular que a gestão pública, muitas vezes, deixa de trabalhar esses aspectos espontâneos e positivos dos servidores. Para Barrett (2000), as pessoas buscam cada vez mais trabalhar para organizações que as encorajem a encontrar suas realizações pessoais, respeitando os seus valores mais nobres e profundos, e promovendo uma ambiência propícia a altos índices de produtividade e criatividade. Apresenta-se como um desafio para a gestão pública, portanto, criar uma cultura que reforce o aspecto do significado do trabalho, favorecendo a diminuição da dicotomia trabalho-prazer.

Após o mapeamento das âncoras dos servidores, encontrou-se, para cada um, o valor que relacionou as âncoras de carreira com as orientações da administração gerencial. Para isso, para cada valor incentivado pelas orientações da administração gerencial (autonomia administrativa, a competitividade, a inovação, a criatividade, a confiança e a meritocracia), obteve-se a média ponderada dos escores de cada âncora, de cada funcionário, lembrando que os pesos e as intensidades do vínculo entre cada orientação e cada âncora foram atribuídos pelos especialistas. Assim foi possível identificar quais valores estão mais ou menos alinhados às âncoras dos funcionários do INCA, resultando no "ranking de valores" apresentados na Tabela 4. 


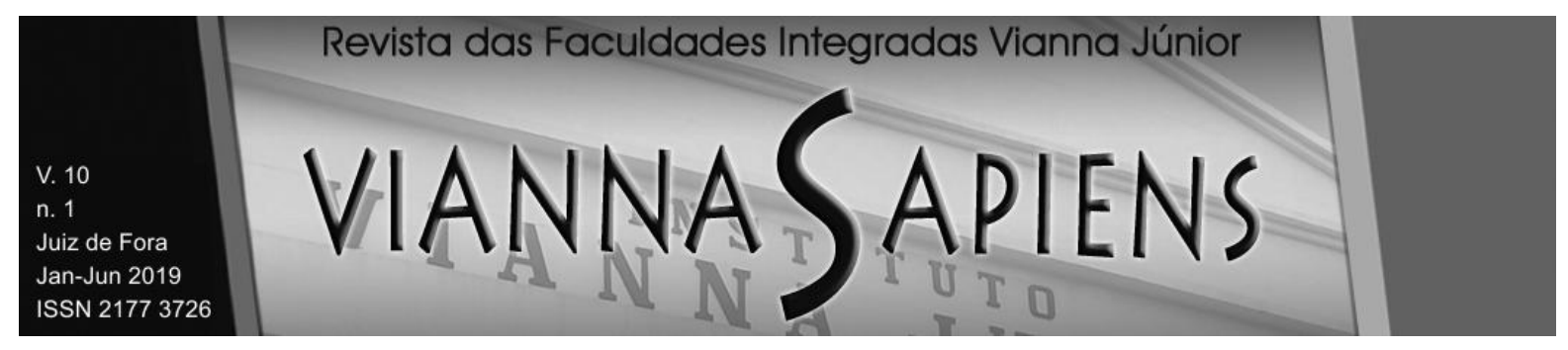

\section{Tabela 4 - Ranking de Valores dos servidores do INCA}

\begin{tabular}{|l|r|}
\hline \multicolumn{1}{|c|}{ Valor } & \multicolumn{1}{c|}{ Média } \\
\hline 10 Autonomia & 3,87 \\
\hline 20 Competitividade & 3,82 \\
\hline 3 Meritocracia & 3,81 \\
\hline 40 Criatividade & 3,72 \\
\hline 5 Inovação & 3,67 \\
\hline 60 Confiança & 3,24 \\
\hline
\end{tabular}

Fonte: Dados da pesquisa

Após identificar-se o ranking de "valores" do INCA, verificou-se, pelos testes de hipóteses para a média, se a média de cada valor incentivado pelas orientações da administração gerencial superou o ponto médio da escala de 1 a $6(3,5)$. Foram realizados cinco, e não seis testes de hipóteses, devido ao fato do valor "Confiança" possuir a média amostral menor do que o ponto médio da escala. Assim, este valor não pode ser considerado alinhado com as âncoras dos servidores, e não há necessidade de conduzir este teste de hipótese.

A Tabela 5 mostra os resultados dos cinco testes de hipóteses unicaudais para a média (alfa $=5 \%$ ). Em cada teste, $\mathrm{HO}$ representa que a média era igual ao ponto médio da escala $(3,5)$ e a $\mathrm{H} 1$ representa que a média era maior que esse ponto médio $(>3,5)$. Observa-se, nos cinco testes de hipóteses (competitividade, inovação, autonomia, meritocracia e competitividade), que $\mathrm{HO}$ foi rejeitado, sendo o valor $p$ resultante menor que $0,1 \%$. 


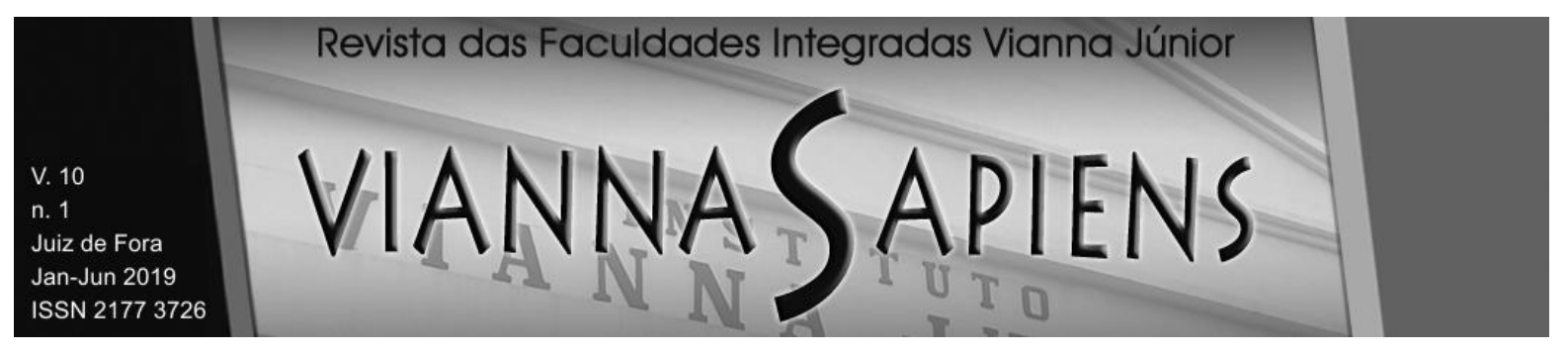

Tabela 5 - Testes de hipótese para a média

\begin{tabular}{|c|c|c|c|c|c|}
\hline & Criatividade & Inovação & Autonomia & Meritocracia & Competitividade \\
\hline HO: media populacional = & 3,5 & 3,5 & 3,5 & 3,5 & 3,5 \\
\hline H1: media populacional > & 3,5 & 3,5 & 3,5 & 3,5 & 3,5 \\
\hline alfa & $5 \%$ & $5 \%$ & $5 \%$ & $5 \%$ & $5 \%$ \\
\hline & & & & & \\
\hline n & 224 & 224 & 224 & 224 & 224 \\
\hline Média amostral & 3,72 & 3,67 & 3,87 & 3,81 & 3,82 \\
\hline Desvio Padrão Amostral & 0,561819814 & 0,559735861 & 0,542030892 & 0,549254745 & 0,557955223 \\
\hline erro padrão & 0,04 & 0,04 & 0,04 & 0,04 & 0,04 \\
\hline$z$ & 5,85 & 4,49 & 10,34 & 8,36 & 8,61 \\
\hline valorp & $0,000000250241 \%$ & $0,000351976667 \%$ & $0,000000000000 \%$ & $0,000000000000 \%$ & $0,000000000000 \%$ \\
\hline
\end{tabular}

Fonte: Dados da pesquisa.

Identifica-se, assim, a compatibilidade das âncoras de carreira dos servidores que atuam nas atividades-fim do INCA com quase todos os valores incentivados pela administração pública gerencial, voltados para a gestão de pessoas e expressos no PDRAE. Salienta-se que somente o valor "Confiança" não está alinhado com as âncoras desses profissionais.

Foram extraídas considerações importantes a respeito da compatibilidade de cinco dos seis valores; obtiveram-se, também, reflexões sobre a homogeneidade do escore entre os valores "Autonomia", "Competitividade", "Meritocracia" "Criatividade", "Inovação" e, ainda, observações relevantes do motivo pelo qual o valor "Confiança" não foi alinhado às âncoras dos servidores do INCA.

Quanto à compatibilidade de quase todos os valores pesquisados com as âncoras dos servidores, depreende-se que este resultado apontou, na amostra e na metodologia proposta, que os profissionais revelam, ao longo desses 20 anos, valores condizentes com os propostos pelo PDRAE. Não se pode dizer que os valores da administração pública gerencial superaram ou substituíram os valores da administração burocrática, porém é possível supor que, a partir dos principais valores encontrados no INCA, essas características já se encontram presentes entre os profissionais de um órgão referência em saúde pública no Brasil. 


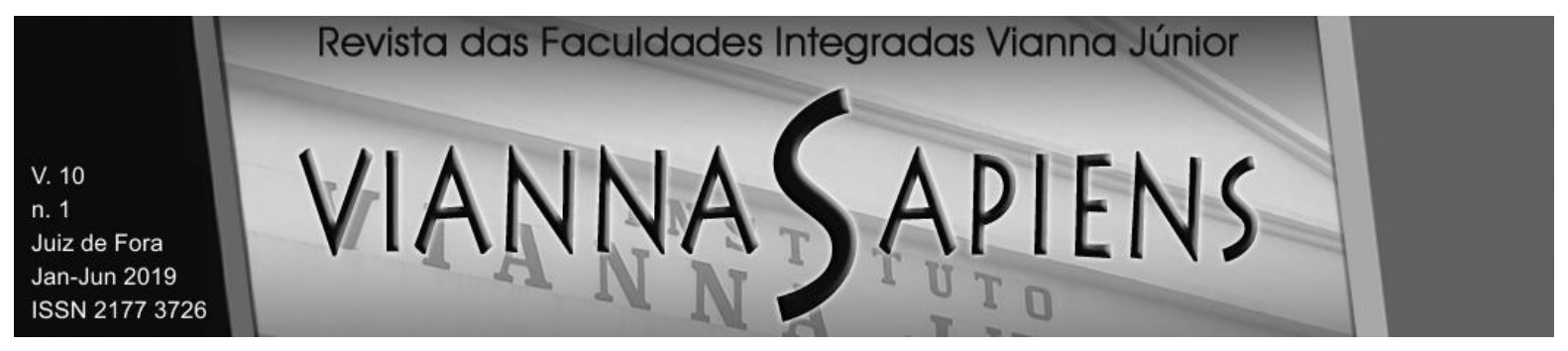

Posteriormente, cabe refletir que os cinco valores compatíveis com as âncoras dos servidores tiveram escores homogêneos, o que pode significar que todos os valores possuem importância para os profissionais da amostra, não havendo significância estatística entre um valor e outro. Assim, se o defendido por alguns autores, como Rezende (2005), estiver correto, essas características baseadas nos padrões e eficiência do setor privado, podem ser responsáveis por uma maior agilidade e flexibilidade no setor público.

Como não há uma série histórica desta pesquisa, não se pode analisar quando esses valores pessoais, voltados para a administração pública gerencial, começaram a fazer parte do contexto do INCA. Dessa forma, não é possível, pelo mesmo motivo, conhecer se, de fato, esta possível aderência aos valores preconizados pela administração pública gerencial trouxe, na hipótese de supressão de valores da administração burocrática, benefícios incrementais para o órgão e para a sociedade nos últimos anos. A partir daí, destaca-se a necessidade de conhecer esses valores ao longo do tempo e de se construir uma série histórica da intensidade dos mesmos, o que permitiria a obtenção de informações sobre uma possível melhoria da eficiência e eficácia dos serviços públicos prestados pelo instituto, a partir dos valores pessoais de seus profissionais.

Ainda neste contexto, podem-se realizar algumas reflexões ao se considerar as conclusões encontradas por Costa, Salles e Fontes Filho (2010), quando especularam, a partir da homogeneidade dos resultados encontrada em suas pesquisas, que esta é decorrente das próprias transformações institucionais que tornam difusos os limites entre setor público e o setor privado. Para eles:

[...] é instigante observar que, apesar das diferenças nas características das organizações públicas, híbridas e privadas, a natureza da motivação, como expectativa de recompensa, e a base valorativa de seus trabalhadores sejam tão similares (COSTA; SALLES; FONTES FILHO, 2010). 


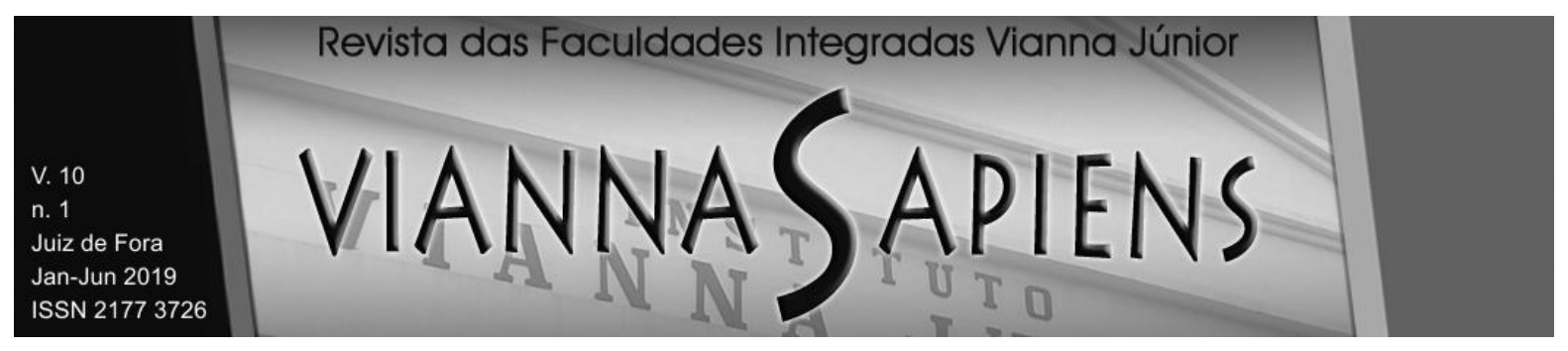

Ou seja, tanto no estudo de Costa, Salles e Fontes Filho (2010), que foi realizado entre 2007 e 2008, quanto no presente estudo, realizado em 2015, encontram-se indícios, nas amostras estudadas, de que não há fortes diferenças quanto às motivações, necessidades e conjunto de valores dos servidores públicos em relação aos profissionais da iniciativa privada, o que pode ser explicado, de acordo com DuGay, Salaman e Rees (1996), apud Costa, Salles e Fontes Filho (2010), pelas mudanças no mercado de trabalho e nas estruturas produtivas, que exigem de todos os profissionais atitudes "proativas", "orientadas ao mercado" e "empreendedoras".

É oportuno pontuar que os resultados e as análises dos resultados encontrados neste estudo são diferentes dos obtidos por Faro (2007). Ele, mediante metodologia própria e respeitando a peculiaridade do órgão pesquisado, investigou as âncoras de carreira dos servidores do Tribunal de Contas da União em 2007 e, apesar de encontrar âncoras semelhantes às deste estudo, sustentou a incompatibilidade entre as principais âncoras de carreira dos servidores e os valores exigidos (teoricamente) pela administração pública gerencial. Esta diferença pode ser explicada, em parte, pelo fato do estudo de Faro (2007), ao contrário do que ocorreu de forma original neste estudo, que considerou a aplicação da lógica Fuzzy (ZIMMERMANN, 1996), não ter verificado a intensidade do vínculo entre cada orientação da administração pública gerencial proposta no PDRAE e cada âncora de carreira proposta por Schein (1996).

A terceira observação refere-se aos motivos que levaram os servidores do INCA a não atribuírem o valor "confiança" às suas âncoras de carreira. Este resultado vai ao encontro de uma consideração de Faro (2007), o qual considerou que o sistema atual de recompensas do TCU gera nos servidores maior resistência às alterações preconizadas pelo modelo da administração pública gerencial.

Pode-se especular que o desalinhamento do valor "Confiança" com as âncoras de carreira dos servidores do INCA esteja relacionado ao contexto do mundo do trabalho. Segundo Sennett (2006) e Van Buren III (2003), as organizações 


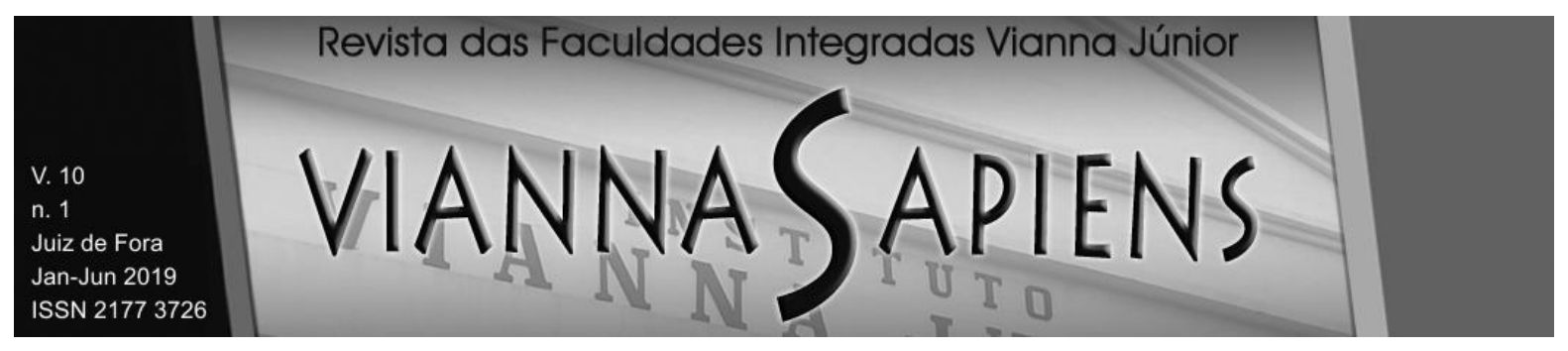

buscam pessoas avessas às perspectivas de longo prazo. E, conforme Ribeiro e Mancebo (2013), neste contexto, a regularidade de uma carreira linear com a atuação em uma única empresa, a especialização em determinada atividade, o planejamento de longo prazo, a segurança em relação ao futuro e a carreira tradicional são afetadas pelo processo de reestruturação produtiva do atual capitalismo flexível. Ou seja, a procura de trabalhadores com este perfil, também por parte de órgãos e entidades públicas, contradizendo a segurança e a estabilidade, até então garantidos no serviço público, pode gerar uma falta de "confiança" por parte dos profissionais do Instituto.

Sabe-se que os servidores públicos possuem a estabilidade na administração pública após a aprovação no estágio probatório; porém, cabe lembrar que a Emenda Constitucional no19 trouxe novos critérios para a aquisição da estabilidade, além da avaliação de desempenho periódica como possibilidade de perda do cargo para o servidor estável. E, embora ainda não se perceba, na prática, os possíveis resultados destas ferramentas, não há como assegurar que elas permanecerão como mera formalidade ao longo dos anos. Além das alterações advindas da Emenda Constitucional no19, pode-se citar que o INCA já demonstrou, em seus estudos para um novo modelo de gestão, interesse em contratar profissionais celetistas (cujas chances de demissões são maiores), por concurso público, acreditando que este método de contratação the traria maior flexibilidade. Cabe reforçar que essa flexibilização e novas formas de contratação podem contribuir para a falta do valor "Confiança" entre os profissionais da área pública.

Pelos motivos expostos acima, pode-se inferir que a falta do valor "Confiança" em servidores públicos, ao menos na amostra pesquisada, pode ser algo novo, oriunda das alterações que ocorreram no contexto do mundo do trabalho atual e de algumas orientações do PDRAE e da Emenda Constitucional oo19 (BRASIL, 1998). Tal fato traz outra suposição interessante: ausente na administração pública durante o modelo da administração burocrática e, possivelmente, sempre presente na administração privada, pela precariedade do vínculo, agora faz parte do contexto da 


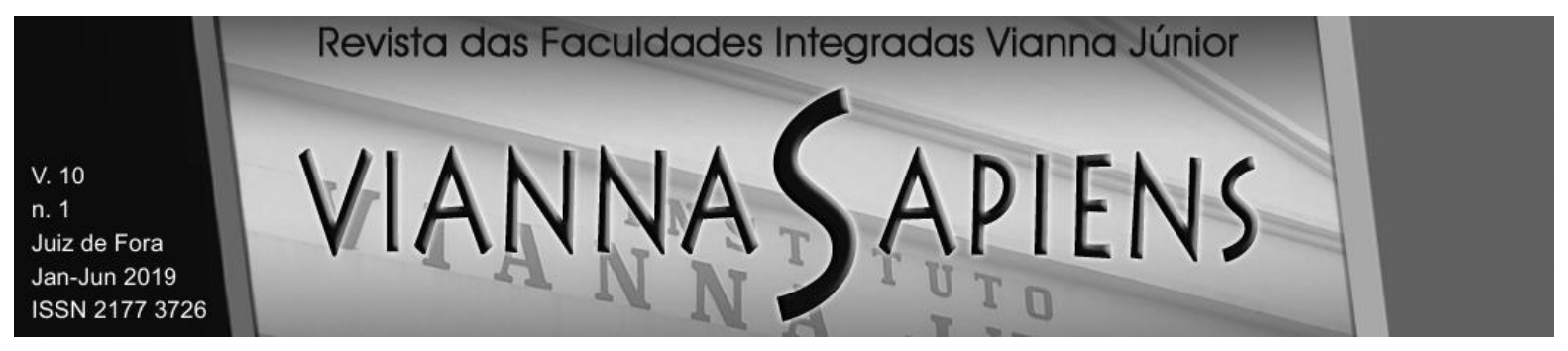

administração pública gerencial e, consequentemente, dos órgãos públicos. Ou seja, além dos valores autonomia, competitividade, criatividade, inovação e meritocracia, já conhecidos e, até então, considerados típicos do setor privado e, possivelmente desejáveis, a administração pública, a partir destas mudanças, passou a contar com a falta do valor "Confiança". Podemos inferir ainda que a falta do valor "Confiança" pode não estar relacionada diretamente às propostas e valores do modelo da administração gerencial, mas sim, às dinâmicas, procedimentos e políticas de gestão do INCA.

Complementando o objetivo desta pesquisa, algumas das informações pessoais, apresentadas preliminarmente (sexo, idade, tempo de experiência na instituição e nível do cargo), foram testadas como possíveis explicadoras da intensidade de cada valor incentivado pela administração pública gerencial presente nos funcionários. Para isso, foram realizadas seis regressões múltiplas (uma para cada valor incentivado pelas orientações da administração gerencial), lembrando que foram utilizadas variáveis dummy para incluir as variáveis sexo e nível do cargo (técnico, técnico superqualificado ou superior) no modelo de regressão.

Após a realização das regressões, pode-se depreender que as características individuais explicam um percentual muito baixo dos valores incentivados pela administração pública gerencial. E, com exceção do valor Confiança, todos os outros cinco valores apresentaram apenas a variável "Masculina" como significativa, com valores de $p$ menores que $5 \%$. Desta maneira, percebeu-se que: os homens apresentaram mais compatibilidade entre as âncoras e os valores propostos pela administração pública gerencial. Este resultado vai ao encontro do trabalho realizado por Oliveira (2007), o qual aponta que o tempo de serviço não aparenta ser relevante para diferenciar os interesses, crenças, valores e objetivos dos servidores públicos. 


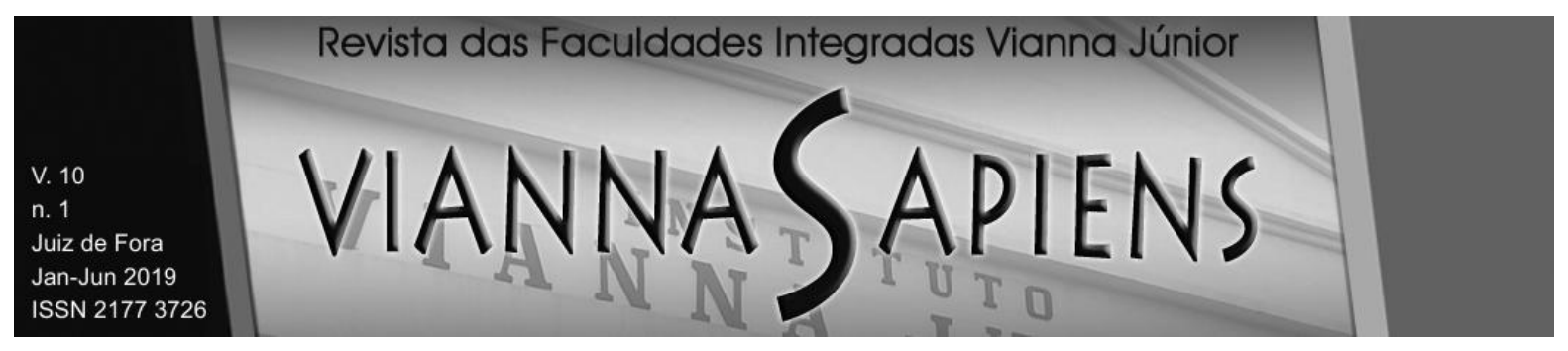

\section{CONCLUSÕES}

Os resultados da pesquisa permitem concluir que as âncoras de carreira dos servidores que atuam nas atividades-fim do INCA são compatíveis com quase todos os valores incentivados pela administração pública gerencial (criatividade, a inovação, a autonomia, a meritocracia e a competitividade) não sendo compatíveis, apenas, com o valor confiança. Quando analisamos o impacto das características individuais sobre a compatibilidade entre as âncoras de carreira e cada um dos valores incentivados pela administração pública gerencial, descobriu-se que apenas o gênero masculino apresentou-se como significativo para a compatibilidade dos valores criatividade, inovação, autonomia, competitividade e meritocracia.

Cabe destacar as diferentes conclusões, contribuições e recomendações que esta pesquisa possibilitou. Podemos concluir, por exemplo, que as características, propostas pelo PDRAE já se encontram presentes nos servidores da área fim e um órgão referência em saúde pública no Brasil o que representa, de certa maneira, uma mudança incremental ao modelo de gestão pública. Além disso, a âncora "senso de dever, dedicação a uma causa" retratou um compromisso de responsabilidade dos servidores do instituto com o trabalho e com a sociedade, diferente de outros estudos que apontaram que 0 atual sistema não permite a assunção de responsabilidades. Já quanto à âncora "estilo de vida", tida como a segunda principal âncora do INCA, pode-se inferir que se deve ao contexto social atual, onde os profissionais buscam o equilíbrio entre o lado pessoal, o trabalho e a família. Ainda cabe destaque para o bom escore da âncora "puro desafio" e do valor "competitividade" que podem retratar os desafios de se trabalhar em uma instituição com qualidade técnica e tecnologia reconhecida.

Quanto à não compatibilidade do valor "confiança" com as âncoras dos servidores das áreas fins do INCA, concluiu-se que podemos ter um fato novo, uma vez que o valor "confiança", tido como uma das características da administração burocrática, caracterizada pela estabilidade e segurança, não está mais presente em 


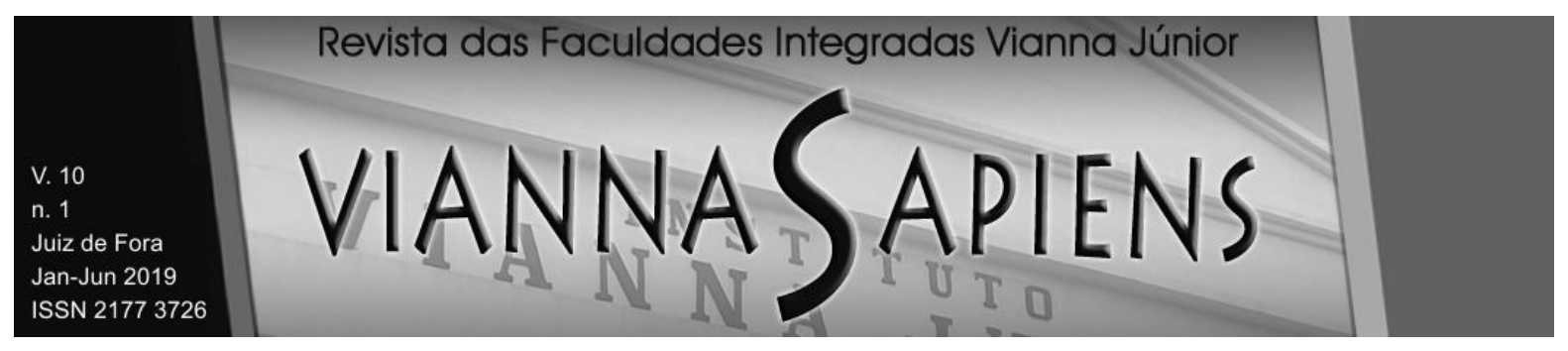

um órgão público. Ou seja, as mudanças advindas do contexto do trabalho atual, das orientações do PDRAE, bem como da Emenda Constitucional №19 (BRASIL, 1998) trouxeram não só os valores tidos como desejáveis da iniciativa privada como a autonomia, criatividade, inovação, meritocracia e competitividade, mas também a falta do valor confiança. Cabe relembrar que as políticas, procedimentos e dinâmicas da gestão interna podem também contribuir para a falta da do valor "confiança".

Em relação à contribuição desta pesquisa, podemos citar que tanto as âncoras dos servidores quanto os valores por eles apresentados contribuem para se fazer convergir os comportamentos efetivos dos servidores do Instituto com aqueles preconizados na administração gerencial. Ainda, no contexto da colaboração desta pesquisa para a construção de um novo modelo de gestão para o INCA, partindo do princípio que são os profissionais que moldarão as características do novo modelo, o estudo permite uma ampla discussão sobre qual o melhor modelo para a instituição, bem como contribui para o direcionamento correto dos esforços de viabilidade da implantação efetiva de práticas da administração gerencial. Outro direcionamento dos esforços, a partir do conhecimento dos perfis e as orientações de carreira de seus profissionais, é o estabelecimento de novas diretrizes para os planos de seleção, desempenho e capacitação.

A pesquisa permitiu, ainda, trazer novas interpretações para a literatura acerca das orientações de carreira dos profissionais públicos no país, além da construção de um método capaz de mensurar os valores, e não somente as âncoras dos profissionais, de qualquer organização. É certo que a discussão acerca do melhor modelo de gestão para a administração pública desperta curiosidades, interesses e controvérsias e, somente com um esforço e debate contínuos, poderse-á construir uma administração pública que atenda aos interesses da sociedade e de seus profissionais.

Por fim, alguns limites da pesquisa devem ser ressaltados. Em primeiro lugar, o fato de a pesquisa ter se concentrado nas atividades fins do INCA, impede a generalização do resultado. $E$, em segundo lugar, a escolha do método e das 


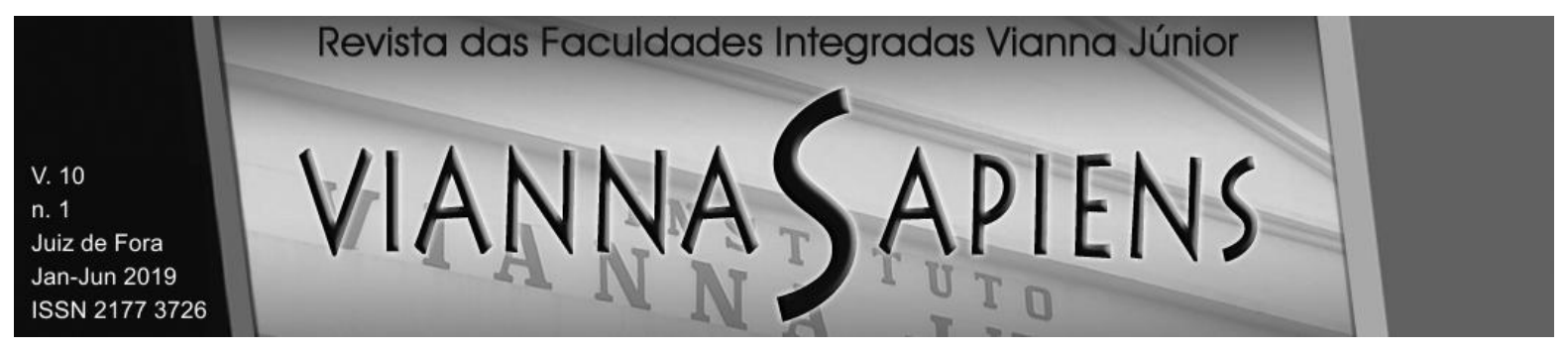

âncoras de carreira não esgotam os temas de valores, necessidades e comportamentos dos servidores. Tendo em vista o exposto, recomenda-se, para estudos futuros, a necessidade de se pesquisar diferentes cargos da administração pública, independente da finalidade das atividades desenvolvidas pelos servidores e do órgão; a indagação do fato do gênero masculino apresentar maior compatibilidade de suas âncoras com os valores da administração pública gerencial; a curiosidade de se conhecer até que ponto o contexto do INCA e a natureza de suas atividades, e não as políticas propostas pelo modelo gerencial, influenciaram nos resultados encontrados, assim como sugere-se a realização de estudos comparativos ao longo do tempo.

\section{REFERÊNCIAS}

ALBRECHT, P.A.T.; KRAWULSKI, E. Concurseiros e a busca por um emprego estável: reflexões sobre os motivos de ingresso no serviço público. Cadernos de Psicologia Social do Trabalho, v.14, n.2, p.211-226, 2011.

AVELINO, K.W.R.S.; SALLES, D.M.R.; COSTA, I.S.A. Collective competencies and strategic people management: a study carried out in federal public organizations.

Revista de Administração Mackenzie, v.18, n.5, p.202-228, 2017.

ABRUCIO, F.L. Trajetória recente da gestão pública brasileira: um balanço crítico e a renovação da agenda de reformas. Rev. Adm. Pública. 41(n.spe), pp.67-86, 2007.

\section{ABDALLA, R.A.C. As âncoras de carreira como instrumento de análise das} decisões profissionais. Dissertação de Mestrado em Administração de Empresas, Escola de Administração de Empresas/Fundação Getúlio Vargas. São Paulo, 2003.

BARRETT, R. Libertando a alma da empresa: como transformar a organização numa entidade viva. São Paulo: Cultrix, 2000. 


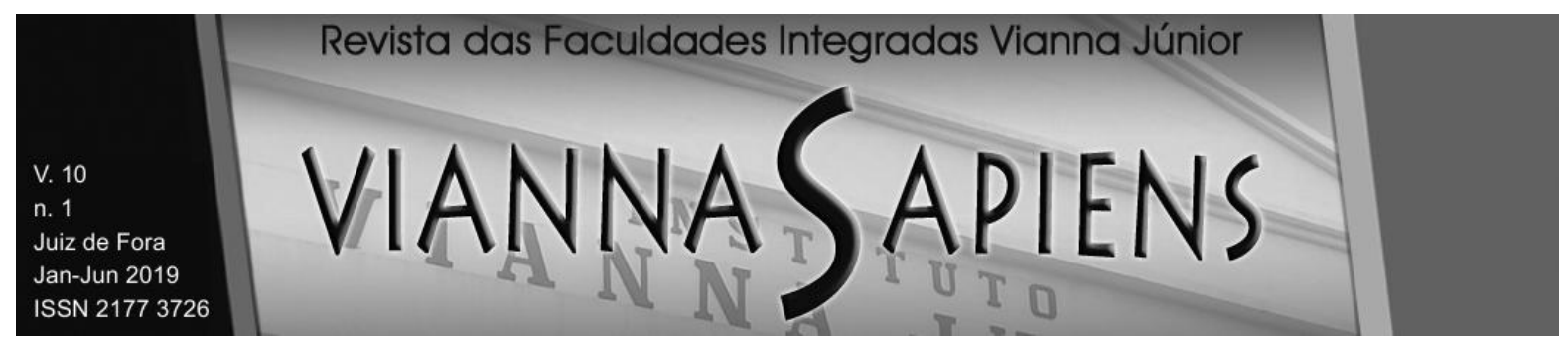

BERGUE, S.T. Gestão estratégica de pessoas no setor público. São Paulo: Atlas, 2014.

BRASIL. Presidência da República. Plano Diretor da Reforma do Aparelho do Estado. Brasília: 1995.

BRASIL. Ministério da Saúde. Portaria no 1.045 de 10 de dezembro de 2012. Institui Grupo de Trabalho com a finalidade de apresentar estudos para novo modelo de gestão do Instituto Nacional de Câncer José Alencar Gomes da Silva (INCA/SAS/MS).

BRASIL. Presidência da República. Emenda Constitucional nª 19 de 04/06/1998. Modifica o regime e dispõe sobre princípios e normas da Administração Pública, servidores e agentes políticos, controle de despesas e finanças públicas e custeio de atividades a cargo do Distrito Federal, e dá outras providências.

BRESSER-PEREIRA, L. C.; SPINK, P. K. Reforma do estado e administração pública gerencial. 4. ed. Rio de Janeiro: FGV, 2006.

COSTA, F. Reforma do Estado e contexto brasileiro: crítica do paradigma gerencialista. Rio de Janeiro: FGV, 2010.

COSTA, I. S. A.; SALLES, D. M. R.; FONTES FILHO, J. R. Influência das configurações organizacionais sobre valores no trabalho e preferências por recompensa. RAP, v.44, n.6, p.1429-52, 2010.

DU GAY, P.; SALAMAN, G.; REES, B. The conduct of management and the management of conduct: contemporary managerial discourse and the constitution of the 'competent' manager. Journal of Management Studies, v. 33, n. 3, 1996.

FARO, E. S. C. Âncoras de carreira e o modelo de administração gerencial: um estudo de caso do Tribunal de Contas da União. Dissertação (Mestrado em Administração) - Pontifícia Universidade Católica de São Paulo, São Paulo, 2007. 


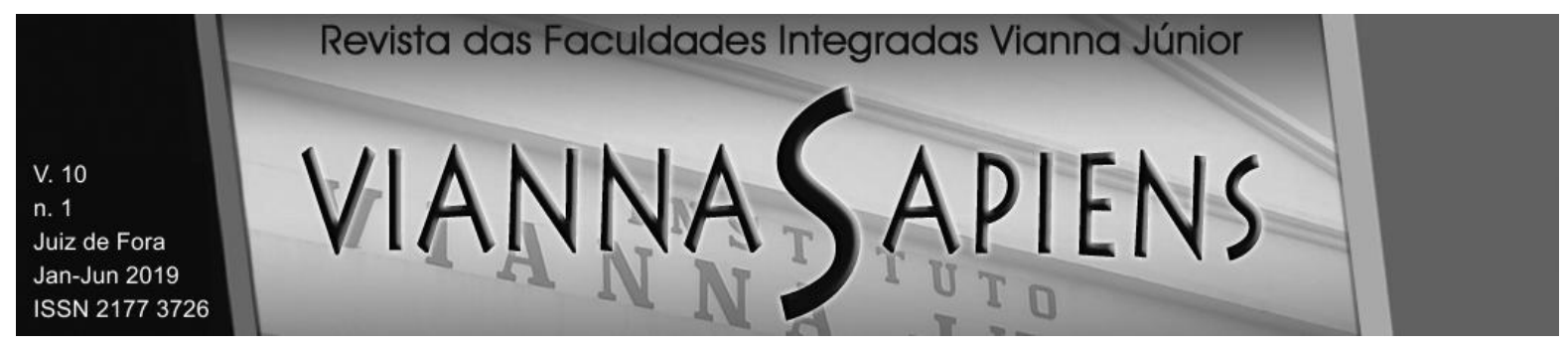

INCA - INSTITUTO NACIONAL DE CÂNCER JOSÉ ALENCAR GOMES DA SILVA. Relatório de atividades: 2013-2014. Rio de Janeiro: INCA, 2015. Disponível em: <www.inca.gov.br>. Acesso em: 27 out. 2017.

KLIR, G. G.; YUAN, B. Fuzzy Sets and Fuzzy Logic: Theory and Applications. Upper Saddle River: Prentice Hall; 1995.

MARCONI, N. Políticas integradas de recursos humanos para o setor público. In: LEVY, E.; DRAGO, P.A. (Org.). Gestão pública no Brasil contemporâneo. São Paulo: Fundap, 2005.

McGREGOR, D. O lado humano da empresa. São Paulo: Martins Fontes, 1999.

MORGAN, G. Imagens da organização. São Paulo: Atlas, 2002.

OLIVEIRA, C. G. O servidor público brasileiro: uma tipologia da burocracia. Revista do Serviço Público, v.58, n. 3, p. 269-302, 2007.

REZENDE, F. C. Tendências da gestão pública nos países da OCDE. In: LEVY, E.; DRAGO, P.A. (org.). Gestão pública no Brasil contemporâneo. São Paulo: Fundap/Casa Civil, 2005.

RIBEIRO, C. V. S; MANCEBO. D. O servidor público no mundo do trabalho do século XXI. Psicologia: Ciência e Profissão, v.33, n.1, p.192-207, 2013.

ROUSSEAU, D. Psychological Contracts in Organizations: Understanding Written and Unwritten Agreements. Thousand Oaks: Sage, 1995.

SCHEIN, E. H. Career anchors and career paths: a panel study of management school graduates. 1974. Working paper (Sloan School of Management); 707-774. Alfred P. Sloan School of Management, Massachusetts Institute of Technology. Disponível em: <http://eric.ed.gov/?id=ED099581>. Acesso em: 18 jul. 2016. 


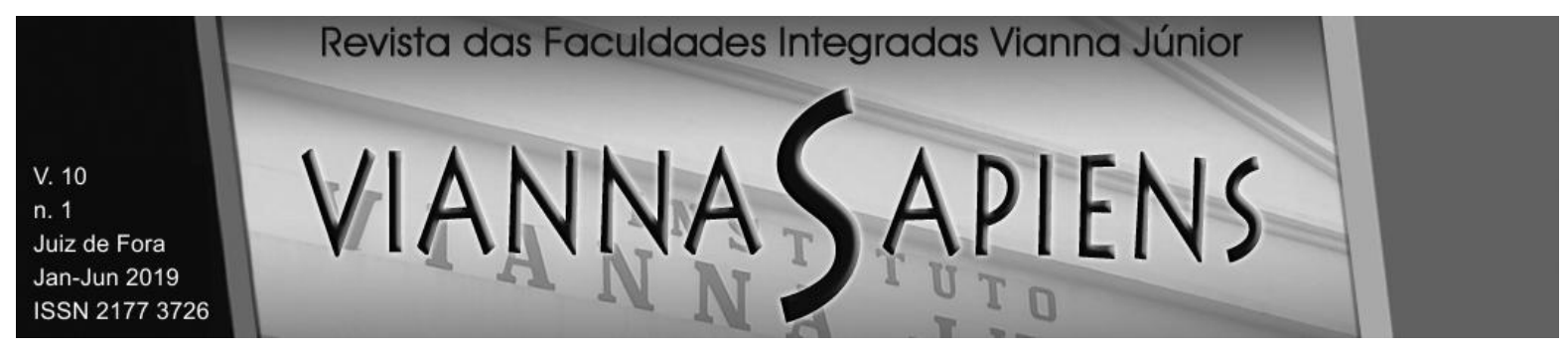

SCHEIN, E. H. Identidade profissional: como ajustar suas inclinações a suas opções de trabalho. São Paulo: Nobel, 1996.

SENNETT, R. A cultura do novo capitalismo. Rio de Janeiro: Record, 2006. VAN BUREN III, H. J. Boundaryless careers and employability obligations. Business Ethics Quarterly, v. 13, n. 2, p. 131-149, Apr./Jun. 2003.

VAN DAM, K. Antecedents and consequences of employability orientation. European Journal of Work and Organizational Psychology, v. 13, n. 1, p. 29-51, 2004.

WITTMER, D. Serving the people or serving for pay: reward preferences among government, hybrid sector, and business managers. Public Productivity \& Management Review, v.14, n.4, p.369-374, 1991.

ZIMMERMANN, H. Fuzzy set theory and its applications. London: Kluwer,1996.

Recebido em 19/02/2019

Publicado em 12/07/2019 